\title{
Effects of pre-existing ice crystals on cirrus clouds and comparison between different ice nucleation parameterizations with the Community Atmosphere Model (CAM5)
}

\author{
X. Shi ${ }^{1,2,3}$, X. Liu ${ }^{1}$, and K. Zhang ${ }^{4}$ \\ ${ }^{1}$ Department of Atmospheric Science, University of Wyoming, Laramie, WY, USA \\ ${ }^{2}$ Hebei Key Laboratory for Meteorology and Eco-environment, Shijiazhuang, China \\ ${ }^{3}$ Hebei Climate Center, Shijiazhuang, China \\ ${ }^{4}$ Atmospheric Science and Global Change Division, Pacific Northwest National Laboratory, Richland, WA, USA \\ Correspondence to: X. Liu (xliu6@uwyo.edu)
}

Received: 12 June 2014 - Published in Atmos. Chem. Phys. Discuss.: 2 July 2014

Revised: 10 November 2014 - Accepted: 5 January 2015 - Published: 11 February 2015

\begin{abstract}
In order to improve the treatment of ice nucleation in a more realistic manner in the Community Atmosphere Model version 5.3 (CAM5.3), the effects of pre-existing ice crystals on ice nucleation in cirrus clouds are considered. In addition, by considering the in-cloud variability in ice saturation ratio, homogeneous nucleation takes place spatially only in a portion of the cirrus cloud rather than in the whole area of the cirrus cloud. Compared to observations, the ice number concentrations and the probability distributions of ice number concentration are both improved with the updated treatment. The pre-existing ice crystals significantly reduce ice number concentrations in cirrus clouds, especially at mid- to high latitudes in the upper troposphere (by a factor of $\sim 10$ ). Furthermore, the contribution of heterogeneous ice nucleation to cirrus ice crystal number increases considerably.

Besides the default ice nucleation parameterization of Liu and Penner (2005, hereafter LP) in CAM5.3, two other ice nucleation parameterizations of Barahona and Nenes (2009, hereafter BN) and Kärcher et al. (2006, hereafter KL) are implemented in CAM5.3 for the comparison. In-cloud ice crystal number concentration, percentage contribution from heterogeneous ice nucleation to total ice crystal number, and pre-existing ice effects simulated by the three ice nucleation parameterizations have similar patterns in the simulations with present-day aerosol emissions. However, the change (present-day minus pre-industrial times) in global annual mean column ice number concentration from the KL parameterization $\left(3.24 \times 10^{6} \mathrm{~m}^{-2}\right)$ is less than that from the
\end{abstract}

$\mathrm{LP}\left(8.46 \times 10^{6} \mathrm{~m}^{-2}\right)$ and $\mathrm{BN}\left(5.62 \times 10^{6} \mathrm{~m}^{-2}\right)$ parameterizations. As a result, the experiment using the KL parameterization predicts a much smaller anthropogenic aerosol longwave indirect forcing $\left(0.24 \mathrm{~W} \mathrm{~m}^{-2}\right)$ than that using the LP $\left(0.46 \mathrm{~W} \mathrm{~m}^{-2}\right)$ and $\mathrm{BN}\left(0.39 \mathrm{~W} \mathrm{~m}^{-2}\right)$ parameterizations.

\section{Introduction}

Cirrus clouds play an important role in the global climate system because they have extensive global coverage (Wang et al., 1996; Wylie and Menzel, 1999). They cool the planet by reflecting the solar radiation back to space and heat the planet by absorbing and re-emitting the long-wave terrestrial radiation (Liou, 1986; Rossow and Schiffer, 1999; Chen et al., 2000; Corti et al., 2005). The balance of these two processes depends mainly on cirrus optical properties and thus on ice crystal number concentration (Haag, 2004; Kay et al., 2006; Fusina et al., 2007; Gettelman et al., 2012). Furthermore, the microphysical properties of cirrus clouds strongly influence the efficiency of dehydration at the tropical tropopause layer and modulate water vapor in the upper troposphere and lower stratosphere (Korolev and Isaac, 2006; Krämer et al., 2009; Jensen et al., 2013).

In recent years, significant progress has been made in both cirrus cloud measurements and cirrus cloud modeling (e.g., Heymsfield et al., 2005; Krämer et al., 2009; DeMott et al., 2011; Cziczo et al., 2013; Jensen et al., 2013; 
Diao et al., 2014; Barahona and Nenes, 2011; Jensen et al., 2012; Spichtinger and Krämer, 2013; Murphy, 2014). Ice crystals may form by both homogeneous freezing of soluble aerosol/droplet particles and heterogeneous ice nucleation on insoluble aerosol particles, called ice nuclei (IN; Pruppacher and Klett, 1997). Laboratory experiments and field observations show that various insoluble or partly insoluble aerosol particles can act as IN under cirrus formation conditions, such as mineral dust, fly ash, and metallic particles (DeMott et al., 2003, 2011; Cziczo et al., 2004; Hoose and Möhler, 2012). Understanding the role of different aerosol types serving as heterogeneous IN in cirrus clouds remains challenging (Szyrmer and Zawadzki, 1997; Kärcher et al., 2007; Hendricks et al., 2011; Hoose and Möhler, 2012; Cziczo et al., 2013). Compared to heterogeneous nucleation, homogeneous nucleation is relatively better understood (Koop et al., 2000; Koop, 2004). The number concentration of soluble aerosol particles in the upper troposphere is usually much higher than that of IN. Once taking place, homogeneous freezing can generate a high number concentration of ice crystals in cold environments with high updraft velocities, and has been assumed to be a dominant process for cirrus cloud formation (Heymsfield et al., 2005; Wang and Penner, 2010; Gettelman et al., 2012). However, heterogeneous nucleation tends to occur at lower supersaturations, and thus prevents the homogeneous nucleation from occurring or reduces the number of ice crystals produced by the homogeneous freezing (Kärcher and Lohmann, 2003; Spichtinger and Gierens, 2009). If the homogeneous nucleation is prevented or how the rate of homogeneously nucleated ice crystals is reduced depends on several parameters, such as number of heterogeneous IN, temperature, or vertical updraft (Liu and Penner, 2005; Kärcher et al., 2006; Barahona and Nenes, 2009). In recent years, the relative contribution of homogeneous nucleation versus heterogeneous nucleation to cirrus cloud formation has attracted a lot of attention. Cziczo et al. (2013) analyzed the residual particle composition (after the ice was sublimated) within cirrus crystals of North and Central America and nearby oceans, and found that heterogeneous freezing was the dominant formation mechanism of these clouds. However, simulations from general circulation models (GCMs) often show that homogeneous freezing is the primary contributor to ice number concentration in cirrus clouds (Lohmann et al., 2008; Hendricks et al., 2011; Liu et al., 2012a; Zhang et al., 2013a; Kuebbeler et al., 2014). The changes in the relative contribution of homogeneous nucleation versus heterogeneous nucleation may have a significant impact on estimating the anthropogenic aerosol indirect effects through cirrus clouds (Liu et al., 2009).

Aerosol indirect effects on cloud properties are one of the largest uncertainties in the projection of future climate change (Lohmann and Feichter, 2005; IPCC, 2007, 2013). There has been significant progress in recent years in developing ice microphysics schemes for GCMs and studying aerosol effects on cirrus clouds (Liu et al., 2007; Get- telman et al., 2010; Salzmann et al., 2010; Wang and Penner, 2010; Hendricks et al., 2011; Ghan et al., 2012; Zhang et al., 2012; Barahona et al., 2014; Shi et al., 2013; Kuebbeler et al., 2014). A key component in cirrus cloud microphysics schemes is the ice nucleation parameterization that links ice number concentration to aerosol properties. Based on theoretical formulations or model simulations of the ice crystal formation process in a rising air parcel, sophisticated ice nucleation parameterizations considering the competition between homogeneous and heterogeneous nucleation have been developed (Liu and Penner, 2005, hereafter LP; Kärcher et al., 2006, hereafter KL; Barahona and Nenes, 2009, hereafter BN). Liu et al. (2012a) studied the impact of heterogeneous dust IN on upper tropospheric cirrus clouds using Community Atmosphere Model version 5 (CAM5) with LP and $\mathrm{BN}$ parameterizations, and found that the impact of heterogeneous dust IN with the LP parameterization is much larger than that with the BN parameterization. Studies of anthropogenic aerosol indirect effects showed that the annual global mean change in long-wave cloud forcing from preindustrial times to present-day estimated from CAM5 with the LP parameterization is $0.40-0.52 \mathrm{~W} \mathrm{~m}^{-2}$ (Ghan et al., 2012), much larger than the estimate $\left(0.05-0.20 \mathrm{~W} \mathrm{~m}^{-2}\right)$ by the ECHAM5-HAM2 model (Zhang et al., 2012) with the KL parameterization (Zhang et al., 2013b). Therefore, it is imperative to find out whether different ice nucleation parameterizations are the main cause for these differences.

Compared to the two other ice nucleation parameterizations ( $\mathrm{LP}$ and $\mathrm{BN}$ ), the KL parameterization considers the effects of pre-existing ice crystals (PREICE) on ice nucleation. The presence of PREICE may hinder homogeneous and heterogeneous nucleation from happening owing to the depletion of water vapor by PREICE. Simulation results from ECHAM with the KL parameterization showed that the PREICE effect leads to cirrus clouds composed of fewer and larger ice crystals (Hendricks et al., 2011; Kuebbeler et al., 2014). Barahona et al. (2014) incorporated the BN parameterization into the NASA Goddard Earth Observing System model version 5 (GEOS5), and modified the original BN parameterization to include the PREICE effect. They showed that cloud forcings are significantly reduced due to the effect of PREICE (Barahona et al., 2014). Because the homogeneous nucleation event usually requires a higher supersaturation than the heterogeneous nucleation, the impact on homogeneous nucleation is stronger than on heterogeneous nucleation. Therefore, considering PREICE may increase the contribution of heterogeneous nucleation to ice crystal formation.

Analysis of in situ data sets obtained in cirrus clouds found that ice saturation ratio, $S_{\mathrm{i}}$, is highly variable both spatially (Jensen et al., 2013) and temporally (Hoyle et al., 2005), and that ice nucleation takes place only in a portion of the cirrus cloud rather than in the whole area of the cirrus cloud (Diao et al., 2013, 2014). However, most GCMs assume that cirrus cloud is homogeneously mixed, and ice nucleation 
event occurs in the whole area of the cirrus cloud (Gettelman et al., 2010; Salzmann et al., 2010; Hendricks et al., 2011; Kuebbeler et al., 2014). Only until recently have GCMs attempted to account for the fraction of cirrus cloud where homogeneous freezing occurs ( $f_{\text {hom }}$ ) (Wang and Penner, 2010; Barahona et al., 2014; Wang et al., 2014).

In this study, in order to improve the treatment of ice nucleation in CAM5, the PREICE effect is considered in the LP parameterization, which is the standard parameterization in CAM5. A method for calculating $f_{\text {hom }}$ is developed, and the impact of $f_{\text {hom }}$ on cirrus cloud properties is investigated. With these modifications, the two unphysical limits (i.e., lower limit of sulfate particles size and upper limit of the characteristic sub-grid updraft velocity) used to drive the LP ice nucleation parameterization are removed. We further investigate the sensitivity of cirrus cloud properties and aerosol indirect forcing through cirrus clouds to different ice nucleation parameterizations (LP, BN, KL) implemented in CAM5. This paper is organized as follows. Model description and modifications are presented in Sect. 2. Model simulations are evaluated and compared with observations in Sect. 3. Section 4 examines the effects of PREICE. Section 5 presents the sensitivity of aerosol indirect effects to different ice nucleation parameterizations. Conclusions are given in Sect. 6.

\section{CAM model and experiments}

\subsection{CAM5}

The model used in this study is the version 5.3 of Community Atmosphere Model (CAM; Neale et al., 2012). The treatment of clouds in CAM5.3 is divided into two categories: convective cloud scheme with simplified cloud microphysics and stratiform cloud scheme with relatively detailed cloud microphysics. Convective microphysics does not consider the effects of aerosol particles on convective cloud droplets and ice crystals. A two-moment stratiform cloud microphysics scheme (Morrison and Gettelman, 2008, hereafter MG; Gettelman et al., 2008, 2010) is used in CAM5.3 and coupled to a modal aerosol module (Liu et al., 2012b) for aerosol-cloud interactions. The default three-mode version of the modal aerosol module, which consists of Aitken, accumulation, and coarse modes, is used in this study. A moisture turbulence scheme (Bretherton and Park, 2009) is used to explicitly simulate the stratus-radiation-turbulence interactions in CAM5. The Rapid Radiative Transfer Model for GCMs (RRTMG) radiation package is used to more accurately take into account aerosol and cloud effects (Iacono et al., 2008).

\subsection{Cirrus cloud scheme in the standard CAM5}

The ice cloud fraction is diagnosed using the total water (water vapor and cloud ice), based on Gettelman et al. (2010). Supersaturation with respect to ice is allowed in the model, and grid-mean relative humidity with respect to ice $\left(\mathrm{RH}_{\mathrm{i}}\right)$ is used in the calculation of deposition growth of ice crystals (Liu et al., 2007). Considering the increase in cloud ice mixing ratio due to vapor deposition during one time step, the growth of ice crystals is calculated using a relaxation timescale (Morrison and Gettelman, 2008; Gettelman et al., 2010). Cloud water from the convective detainment at temperatures below $-30{ }^{\circ} \mathrm{C}$ is assumed to be cloud ice with a prescribed mean radius (Gettelman et al., 2010).

Ice nucleation for cirrus clouds is based on the LP parameterization, which includes the competition between homogeneous nucleation on sulfate and heterogeneous nucleation (immersion freezing) on dust. LP parameterization is derived from fitting the simulation results of a cloud parcel with constant updraft velocities. The number of nucleated ice crystals is a function of relative humidity, temperature, aerosol number concentration, and updraft velocity. Since the current CAM5 model grid cannot resolve the sub-grid scale variability of vertical velocity, $W_{\text {sub }}$, it is diagnosed from the square root of the turbulent kinetic energy calculated in the moisture turbulence parameterization in CAM5.3 (Bretherton and Park, 2009). An upper limit of $0.2 \mathrm{~m} \mathrm{~s}^{-1}$ is assumed for $W_{\text {sub }}$ to fit to the observed ice number concentrations (Gettelman et al., 2010). Dust in the coarse aerosol mode is taken as potential heterogeneous IN. Homogeneous nucleation uses the sulfate aerosol particles in the Aitken mode with diameter greater than $0.1 \mu \mathrm{m}$. The purpose of using this size limit is also to fit to observed ice number concentrations (Gettelman et al., 2010). The cloud droplet activation in warm liquidphase clouds only happens at the cloud base of pre-existing clouds or in all levels of newly formed clouds, as represented in CAM5. In comparison, ice nucleation is allowed to happen in all levels of pre-existing cirrus clouds in CAM5 if the nucleation thresholds are met because $\mathrm{RH}_{\mathrm{i}}$ up to or even more than $120 \%$ are frequently observed inside cirrus clouds (Krämer et al., 2009). The ice number concentration calculated from the ice nucleation parameterization, $N_{a a i}$, is assumed to be the maximum in-cloud ice number concentration in the current time step. New ice crystals will be produced if the in-cloud ice number concentration, $N_{\mathrm{i}}$, from the previous time step falls below $N_{\text {aai }}$. This is described in Eq. (1) as

$\frac{\mathrm{d} N_{\mathrm{i}}}{\mathrm{d} t}=\max \left(0, \frac{N_{\mathrm{aai}}-N_{\mathrm{i}}}{\mathrm{d} t}\right)$.

\subsection{Modifications to the standard ice nucleation parameterization in CAM5}

In this study, several modifications have been made in the ice nucleation scheme in CAM5. First, the effect of PREICE is taken into account, which will be introduced in the next 
subsection. Second, the lower limit ( $0.1 \mu \mathrm{m}$ diameter) of sulfate particles size used for homogeneous freezing is removed. We use the number concentration of all sulfate aerosol particles in the Aitken mode as an input for homogeneous nucleation. This is consistent with the LP parameterization, which is derived for the background sulfate aerosol particles with a lognormal size distribution. Third, the upper limit $\left(0.2 \mathrm{~m} \mathrm{~s}^{-1}\right)$ of $W_{\text {sub }}$ is also removed because updraft velocities measured from several aircraft campaigns show frequent occurrence of larger values (>0.2 $\mathrm{m} \mathrm{s}^{-1}$; Zhang et al., 2013b). Finally, in situ observations of cirrus clouds show that only a small fraction of in-cloud $S_{\mathrm{i}}$ data surpasses the homogeneous freezing saturation threshold ( $S_{\text {hom }}$; Diao et al., 2013). So, we assume that the homogeneous freezing takes place only in a fraction of cirrus clouds $\left(f_{\text {hom }}\right)$ where in-cloud $S_{\mathrm{i}}>S_{\mathrm{hom}} . S_{\mathrm{hom}}$ is the $\mathrm{RH}_{\mathrm{i}}$ threshold for a homogeneous ice nucleation event and it is a function of temperature (Kärcher and Lohmann, 2002a, b). The in-cloud $S_{\mathrm{i}}$ variability can be calculated from the temperature standard deviation, $\delta_{T}$, following Kärcher and Burkhardt (2008):

$$
\begin{aligned}
S_{\mathrm{i}}\left(T^{\prime}\right) & \cong S_{0} \exp \left[\frac{\left(T_{0}-T^{\prime}\right) \theta}{T_{0}^{2}}\right], \\
\frac{\mathrm{d} P_{T^{\prime}}}{\mathrm{d} T^{\prime}} & =\frac{1}{\delta_{T}} \frac{1}{\sqrt{2 \pi}} \exp \left[-\frac{\left(T_{0}-T^{\prime}\right)^{2}}{2 \delta_{T}^{2}}\right],
\end{aligned}
$$

where $T_{0}$ and $S_{0}$ are mean in-cloud temperature and ice saturation, respectively; $T^{\prime}$ and $S_{\mathrm{i}}\left(T^{\prime}\right)$ represents local incloud quantities; $\frac{\mathrm{d} P_{T^{\prime}}}{\mathrm{d} T^{\prime}}$ indicates the temperature probability distribution function (PDF); and $\theta=6132.9 \mathrm{~K}$. The PDFs of $T^{\prime}$ and $S_{\mathrm{i}}\left(T^{\prime}\right)$ can be found in Fig. 3 of Kärcher and Burkhardt (2008). Here, we assume that $T_{0}$ is equal to the model grid temperature and $\delta_{T}$ is uniformly applied to the whole grid area. $S_{0}$ is assumed to be 1.0 because the water vapor deposition on ice crystals will remove supersaturation inside clouds with a long model time step $(30 \mathrm{~min})$ in CAM5. According to the measurement-based analysis of Hoyle et al. (2005), $\delta_{T}$ is calculated from the diagnosed $W_{\text {sub }}$, $\delta_{T} \cong 4.3 W_{\text {sub. }}$. The PDF of $S_{\mathrm{i}}$ can be constructed based on Eq. (2). By comparing $S_{\mathrm{i}}$ and $S_{\text {hom }}$, we can easily calculate the $f_{\text {hom }}$, which is the probability of $S_{\mathrm{i}}>S_{\mathrm{hom}}$. Because the ice number concentration after an ice nucleation event indicates the in-cloud value, the ice number concentration calculated from homogenous freezing parameterization is multiplied by $f_{\text {hom. }}$. In this way, we assume that the cirrus cloud is homogeneously mixed after a nucleation event. We note that the in-cloud $S_{\mathrm{i}}$ variability due to the spatial variability of water vapor is not considered, which can be important as suggested by recent studies (e.g., Diao et al., 2014).

\subsection{Effect of PREICE on ice nucleation}

To account for the effect of PREICE we introduce PREICE into CAM5 based on the concept of Kärcher et al. (2006), which is derived from an adiabatic rising air parcel. Without the PREICE effect, the temporal evolution of $S_{\mathrm{i}}$ is governed by (Kärcher et al., 2006)

$\frac{\mathrm{d} S_{\mathrm{i}}}{\mathrm{d} t}=a_{1} S_{\mathrm{i}} W-\left(a_{2}+a_{3} S_{\mathrm{i}}\right) \frac{\mathrm{d} q_{\mathrm{i}, \text { nuc }}}{\mathrm{d} t}$,

where the parameters $a_{1}, a_{2}$, and $a_{3}$ depend only on the ambient temperature $(T)$ and pressure $(P) ; W$ is the updraft velocity; and $\frac{\mathrm{d} q_{\mathrm{i}, \text { nuc }}}{\mathrm{d} t}$ denotes the growth rate of newly nucleated ice crystals. Note that the sedimentation of ice crystals out of the rising parcel is not considered during a nucleation event. To account for the PREICE effect, the depositional growth of PREICE, $\frac{\mathrm{d} q_{\mathrm{i}, \mathrm{pre}}}{\mathrm{d} t}$ is added to Eq. (4)

$$
\frac{\mathrm{d} S_{\mathrm{i}}}{\mathrm{d} t}=a_{1} S_{\mathrm{i}} W-\left(a_{2}+a_{3} S_{\mathrm{i}}\right)\left(\frac{\mathrm{d} q_{i, n u c}}{\mathrm{~d} t}+\frac{\mathrm{d} q_{\mathrm{i}, \mathrm{pre}}}{\mathrm{d} t}\right) .
$$

Equation (5) can be rewritten in the following form

$$
\begin{aligned}
& \frac{\mathrm{d} S_{\mathrm{i}}}{\mathrm{d} t}=a_{1} S_{\mathrm{i}}\left(W-W_{\mathrm{i}, \mathrm{pre}}\right)-\left(a_{2}+a_{3} S_{\mathrm{i}}\right) \frac{\mathrm{d} q_{i, n u c}}{\mathrm{~d} t}, \\
& W_{\mathrm{i}, \text { pre }}=\frac{a_{2}+a_{3} S_{\mathrm{i}}}{a_{1} S_{\mathrm{i}}} \frac{\mathrm{d} q_{\mathrm{i}, \mathrm{pre}}}{\mathrm{d} t} .
\end{aligned}
$$

Compared to Eq. (4), Eq. (6) indicates that the PREICE effect can be parameterized by reducing the vertical velocity for ice nucleation. This vertical velocity reduction, $W_{\mathrm{i}, \text { pre }}$, caused by PREICE is calculated by Eq. (7).

Assuming all pre-existing ice crystals have the same radius $\left(R_{\mathrm{i}, \text { pre }}\right)$, their growth rate is given by

$$
\frac{\mathrm{d} q_{\mathrm{i}, \text { pre }}}{\mathrm{d} t}=\frac{4 \pi \rho_{\mathrm{i}}}{m_{\mathrm{w}}} n_{\mathrm{i}, \text { pre }} R_{\mathrm{i}, \text { pre }}^{2} \frac{b_{1}}{1+R_{\mathrm{i}, \mathrm{pre}} b_{2}},
$$

where $n_{\mathrm{i} \text {,pre }}$ is the PREICE number concentration, $\rho_{\mathrm{i}}$ is ice density, and $m_{\mathrm{w}}$ is the mass of a water molecule. $b_{1}=$ $\alpha v_{t h} n_{\text {sat }}\left(S_{\mathrm{i}}-1\right) / 4, b_{2}=\alpha v_{\text {th }} /(4 D), \alpha$ is the water vapor deposition coefficient on ice, $v_{\text {th }}$ is their thermal speed, $n_{\text {sat }}$ is the water vapor number density at ice saturation, and $D$ is the water vapor diffusion coefficient from the gas to ice phase (Kärcher et al., 2006). Note that Eqs. (5)-(8) represent an adiabatic rising air parcel with PREICE. We need the $W_{\mathrm{i} \text {,pre }}$ for the ice nucleation parameterization. In the LP ice nucleation parameterization, ice number produced from the homogeneous freezing is a function of temperature, sulfate number concentration, and updraft velocity. To calculate the corresponding $W_{\mathrm{i} \text {,pre, }}, S_{\mathrm{hom}}$ is used in Eqs. (7)-(8). $n_{\mathrm{i} \text {,pre }}$ and $R_{\mathrm{i} \text {,pre }}$ in Eq. (8) indicate the number concentration and radius of in-cloud PREICE, respectively, from the previous time step. $W_{\mathrm{i}, \text { pre }}$ used for heterogeneous nucleation is calculated based on the same approach, except that $S_{\mathrm{i}}$ in Eqs. (7)-(8) is replaced by the heterogeneous freezing saturation threshold, $S_{\text {het }}$.

Figure 1 shows $W_{\mathrm{i}, \text { pre }}$ as a function of PREICE number concentration calculated using Eqs. (7)-(8) at $S_{\text {hom }}$ and $S_{\text {het }}$. $S_{\text {hom }}$ is a function of temperature (Kärcher and Lohmann, 


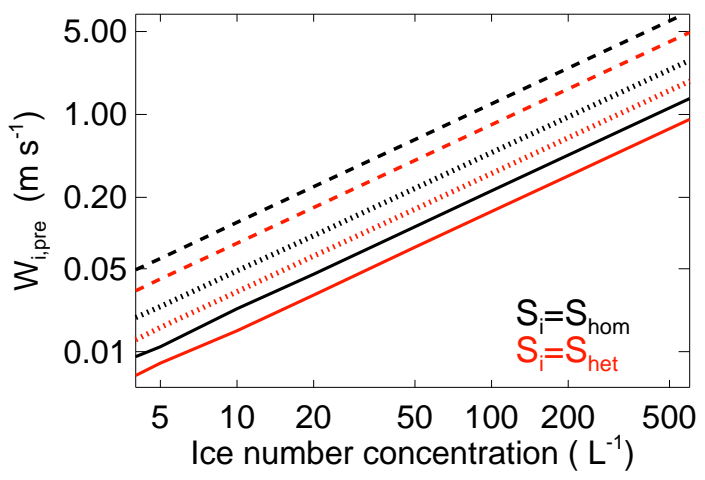

Figure 1. Vertical velocity reduction caused by $\operatorname{PREICE}\left(W_{\mathrm{i}, \text { pre }}\right)$ as a function of ice number concentration. Results are shown for different ice radii, $10 \mu \mathrm{m}$ (solid line), $25 \mu \mathrm{m}$ (dotted line) and $50 \mu \mathrm{m}$ (dash line). The ambient condition is that $T=-60^{\circ} \mathrm{C}, P=230 \mathrm{hpa}$, $S_{\mathrm{i}}=S_{\text {het }}\left(\right.$ red) and $S_{\mathrm{i}}=S_{\text {hom }}$ (black).

2002a, b), and is 1.53 at $T=-60{ }^{\circ} \mathrm{C}$. For immersion freezing of coated dust particles, $S_{\text {het }}$ varies between 1.15 and 1.7 (Hoose and Möhler, 2012; Kuebbeler et al., 2014). Here, $S_{\text {het }}$ is assumed to be 1.3. The most distinct feature of this figure is that $W_{\mathrm{i} \text {,pre }}$ is proportional to the PREICE number concentration. When the PREICE number concentration is greater than $50 \mathrm{~L}^{-1}$ and $W$ less than $0.2 \mathrm{~m} \mathrm{~s}^{-1}$, the black dotted line (for homogeneous freezing and PREICE radius of $25 \mu \mathrm{m}$ ) indicates that homogeneous freezing can not occur, because $W_{\text {i,pre }}>W$.

In the MG scheme, ice crystals are assumed to follow a gamma size distribution and uniformly distributed in cirrus clouds (Morrison and Gettelman, 2008). Thus, an effective radius ( $R_{\text {ieff,pre }}$ ) is used to account for the PREICE size distribution. Because $R_{\mathrm{i} \text {,pre }} \times b_{2}$ in Eq. (8) is usually far greater than 1 (not shown), $\frac{\mathrm{d} q_{\mathrm{i}, \text { pre }}}{\mathrm{d} t}$ is proportional to the first order

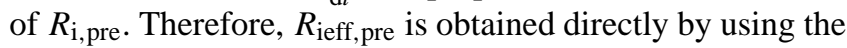
first moment of ice particle size distribution $(0.5 / \lambda, \lambda$ is the slope parameter of Eq. (1) in Morrison and Gettelman, 2008). We note that this $R_{\text {ieff,pre }}$ is different from the effective radius used in the radiative transfer scheme which is calculated from the third and second moments of size distribution. After rearranging the formula used for calculating $\lambda$ (Eq. (3) in Morrison and Gettelman, 2008), $R_{\text {ieff,pre }}$ is calculated based on the following formula:

$R_{\text {ieff,pre }} \cong \frac{1}{2}\left(\frac{q_{\mathrm{i}, \mathrm{pre}}}{\pi \rho_{\mathrm{i}} n_{\mathrm{i}, \mathrm{pre}}}\right)^{1 / 3}$.

Figure 2 shows the schematic diagram of cirrus cloud evolution and the impact of PREICE. Ice crystal numbers are from a short CAM5 simulation. In the default CAM5 that neglects the PREICE effect, ice number produced from the ice nucleation is $1243 \mathrm{~L}^{-1}$ at the beginning time step $t_{1}$. During the next time step $\left(t_{2}\right)$, due to sedimentation of ice crystals (and/or other sink processes), $N_{\mathrm{i}}$ is reduced to $1174 \mathrm{~L}^{-1}$.
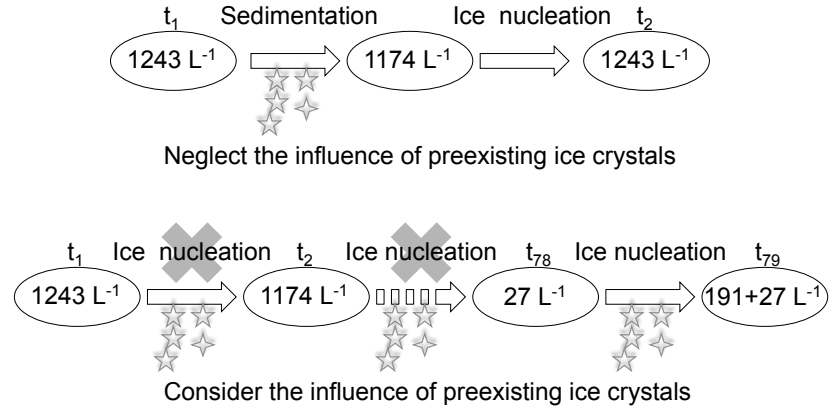

Figure 2. Schematic diagram of cirrus cloud evolution. Upper panel represents the default ice nucleation scheme that neglects the influence of PREICE; lower panel represents the updated scheme that considers the PREICE effect. Ice crystal number concentrations are shown inside the ovals. Time steps are shown above the ovals. All numbers are based on cirrus cloud evolution within a model grid cell $\left(3^{\circ} \mathrm{N}, 75^{\circ} \mathrm{W}, \sim 198 \mathrm{hPa}, \sim 217 \mathrm{~K}\right)$. In this experiment, the updraft velocity is set to $0.2 \mathrm{~m} \mathrm{~s}^{-1}$ and the sulfate number concentration is set to $100 \mathrm{~cm}^{-3}$. Heterogeneous nucleation is not taken into account. The simulation is run 3 months. Just one cirrus cloud evolution process is shown here.

However, with the homogeneous nucleation occurring at $t_{2}$, $N_{\mathrm{i}}$ is increased back to $1243 \mathrm{~L}^{-1}$ according to Eq. (1). In the updated ice nucleation scheme, because the PREICE effect is considered, homogeneous ice nucleation will not happen until $N_{\mathrm{i}}$ is reduced from 1243 to $27 \mathrm{~L}^{-1}$ at the 78 th time step $\left(t_{78}\right)$. After this moment, the PREICE number $\left(\leq 27 \mathrm{~L}^{-1}\right)$ is too low to prevent ice nucleation, so ice nucleation occurs at $t_{79}$. Note that the newly formed ice crystal number concentration is 191 instead of $1243 \mathrm{~L}^{-1}$ because of the presence of PREICE with the number concentration of $27 \mathrm{~L}^{-1}$. The presence of PREICE with concentration of $27 \mathrm{~L}^{-1}$ reduces the vertical velocity $\left(W-W_{\mathrm{i}, \text { pre }}\right)$ used for calculating homogeneous freezing ice crystal number concentration. Here the total $N_{\mathrm{i}}$ is the number concentration of newly formed ice crystals $\left(191 \mathrm{~L}^{-1}\right)$ plus the number concentration of PREICE $\left(27 \mathrm{~L}^{-1}\right)$.

\subsection{Other ice nucleation parameterizations in CAM5}

In order to investigate the sensitivity of model simulated anthropogenic aerosol effects through cirrus clouds to using different ice nucleation parameterizations, $\mathrm{BN}$ and $\mathrm{KL}$ ice nucleation parameterizations are implemented in CAM5.3. The BN parameterization is derived from an approximation to the analytical solution of air parcel equations. This parameterization calculates the maximum ice saturation ratio and nucleated ice crystal number concentration explicitly in the rising air parcel and considers the competition between homogeneous and heterogeneous freezing (Barahona and Nenes, 2009). One advantage of BN parameterization is that the heterogeneous nucleation can be described by different nucleation spectra, derived either from the classical 
nucleation theory $(\mathrm{CNT})$ or from observations (e.g., Meyers et al., 1992; Phillips et al., 2008). In this work, the nucleation spectra based on CNT is used to describe the immersion freezing on dust particles. Furthermore, the BN parameterization used in this study has been modified to consider the effects of PREICE by reducing the vertical velocity for ice nucleation (Barahona et al., 2014).

The KL parameterization is also implemented in CAM5.3. In this parameterization, the competition between different freezing mechanisms and the effects of PREICE are treated by explicitly calculating the evolution of $S_{\mathrm{i}}$ within one hostmodel's time step (e.g., $30 \mathrm{~min}$ ). Compared to LP and BN parameterizations, this method is computationally more expensive. It is necessary to point out that, in the KL parameterization, the ice crystal number concentration produced via homogeneous freezing is not sensitive to the sulfate aerosol number concentration in most cases except for the highest $\left(4 \mathrm{~m} \mathrm{~s}^{-1}\right.$ ) updraft velocities (Fig. 4 and Table 1 in Kärcher and Lohmann, 2002a). As compared to the KL parameterization, the ice number concentrations from both $\mathrm{BN}$ and LP parameterizations are relatively more sensitive to sulfate aerosol number concentration (Fig. 9 in Barahona and Nenes, 2008; Fig. 2 in Liu and Penner, 2005).

The effect of PREICE through $W_{i \text {,pre }}$ is included in LP, $\mathrm{BN}$ and KL parameterizations. All sulfate aerosol particles in the Aitken mode are used for the homogeneous nucleation in these three ice nucleation parameterizations. In order to be consistent with the LP parameterization, only the dust particles in the coarse mode are taken as potential heterogeneous IN in BN and KL parameterizations. To compare with LP and KL under the same condition, the parameter that sets an upper limit on the freezing fraction of potential dust IN in the BN parameterization is set to $100 \%$. The $f_{\text {hom }}$ used for the LP parameterization, as discussed in Sect. 2.3, is also used for BN and KL parameterizations. Note that LP, BN and KL parameterizations are applied only for cirrus clouds. For mixed-phased clouds, we use the default heterogeneous nucleation formulations in CAM5.

\subsection{Description of experiments}

All simulations in this study have been carried out at $0.9^{\circ} \times$ $1.25^{\circ}$ horizontal resolution with 30 vertical levels and a 30 min time step, using prescribed present-day sea surface temperatures. Each experiment has a pair of simulations driven by present-day (the year of 2000) and pre-industrial (the year of 1850) aerosol and precursor emissions from Lamarque et al. (2010), separately. Without specification, the present-day model results are being discussed. All simulations are run for 6 years, and results from the last 5 years are used in the analysis.

Table 1 lists all experiments presented in this study. Compared to the Default experiment, the Preice experiment removes the two unphysical limits (i.e., the lower limit of sulfate particle size distribution and the upper limit of $W_{\text {sub }}$ )
Table 1. List of experiments conducted in this study.

\begin{tabular}{lllll}
\hline Experiment & Two limits & PREICE & $f_{\text {hom }}$ & $\begin{array}{l}\text { Ice } \\
\text { parameterization }\end{array}$ \\
\hline Default & Yes & No & No & LP \\
Preice & No & Yes & Yes & LP \\
NoPreice & No & No & Yes & LP \\
Nofhom & No & Yes & No & LP \\
PreiceBN & No & Yes & Yes & BN \\
NoPreiceBN & No & No & Yes & BN \\
PreiceKL & No & Yes & Yes & KL \\
NoPreiceKL & No & No & Yes & KL \\
\hline
\end{tabular}

used in the ice nucleation parameterization in the default CAM5, and considers PREICE and $f_{\text {hom }}$. This experiment includes a combination of all our updates to the ice nucleation parameterization. Compared to the Preice experiment, NoPreice is used to examine the effects of PREICE, and Nofhom used to examine the effects of $f_{\text {hom }}$. Experiments PreiceBN, NoPreiceBN, PreiceKL and NoPreiceKL are used to examine the PREICE effects in simulations with $\mathrm{BN}$ and KL ice nucleation parameterizations (Sect. 4). The experiments Default, Preice, PreiceBN and PreiceKL are used to compare the model performance among the three ice nucleation parameterizations (Sect. 5).

\section{Model evaluations}

First, we evaluate $W_{\text {sub }}$ used for driving the ice nucleation parameterization and in-cloud $N_{\mathrm{i}}$ predicted by CAM5.3 with the default and updated ice nucleation parameterization. Aircraft measurements from the US Department of Energy (DOE) Atmospheric Radiation Measurement Program (ARM) Small Particles in Cirrus (SPARTICUS) campaign (http://acrf-campaign.arm.gov/sparticus/) for the period of January to July 2010 are used to compare with model results. During the SPARTICUS campaign, ice crystal number and size distribution as well as ambient meteorological variables were routinely measured over the ARM Southern Great Plains (SGP) site $\left(36.6^{\circ} \mathrm{N}, 97.5^{\circ} \mathrm{W}\right)$. Shattering of ice crystals was taken into account through usage of a new twodimensional stereo-imaging probes (2D-S) and improved algorithms (Lawson, 2011). To compare with the aircraft measurements, we sample instantaneous $W_{\text {sub }}$ and $N_{\mathrm{i}}$ over the SGP site every $3 \mathrm{~h}$ from model simulations for the period of January to July.

In CAM5, the characteristic updraft velocity $W_{\text {sub }}$ is calculated for a GCM grid that is much larger than the spatial scale represented by the aircraft data; therefore, it is very difficult to directly compare them. In order to minimize the scale difference, following Zhang et al. (2013b), aircraft data collected during each flight are averaged over a $50 \mathrm{~km}$ grid to derive the statistics of measured vertical velocity. Note that only the updraft portion is counted to get the mean updraft 
velocity. In the Default experiment, the upper limit of $W_{\text {sub }}$ is $0.2 \mathrm{~m} \mathrm{~s}^{-1}$. Because the bin size is $0.06 \mathrm{~m} \mathrm{~s}^{-1}$, the cutoff in Default is not exactly $0.2 \mathrm{~m} \mathrm{~s}^{-1}$ but $0.24 \mathrm{~m} \mathrm{~s}^{-1}$ (Fig. 3, upper panel). However, aircraft measurements show that half $(\sim 55 \%)$ of updraft velocity data surpasses $0.24 \mathrm{~m} \mathrm{~s}^{-1}$. Thus, it is imperative to remove the upper limit of $W_{\text {sub }}$. In other experiments without this upper limit, the occurrence frequency of $W_{\text {sub }}$ deceases with increasing $W_{\text {sub }}$, and agrees well with observation data (Fig. 3, upper panel). In the first smallest bin $\left(<0.06 \mathrm{~m} \mathrm{~s}^{-1}\right)$, the modeled occurrence frequency of $W_{\text {sub }}$ is less than observations. However, the influence of this difference on ice nucleation is small because ice nucleation events are significantly reduced in this lower updraft range $\left(<0.06 \mathrm{~m} \mathrm{~s}^{-1}\right)$ due to the effect of PREICE (Fig. 6).

$N_{\mathrm{i}}$ from Default is mainly distributed in the range of 5$100 \mathrm{~L}^{-1}$, and the occurrence frequency of $N_{\mathrm{i}}$ at higher number concentrations $\left(>100 \mathrm{~L}^{-1}\right)$ is significantly lower than observations (Fig. 3, lower panel). In the Preice experiment, $\sim 11 \%$ of $N_{\mathrm{i}}$ is higher than $100 \mathrm{~L}^{-1}$, which is significantly larger than that in Default $(\sim 3 \%)$. The main reason is that Preice removes the two unphysical limits used for reducing the ice number concentrations. Although the occurrence frequency of $N_{\mathrm{i}}>100 \mathrm{~L}^{-1}$ from Preice is still lower than observations $(\sim 30 \%)$, its modeled histogram agrees better with the observations than Default. Compared to Preice, the occurrence frequency of $N_{\mathrm{i}}>100 \mathrm{~L}^{-1}$ from NoPreice $(\sim 40 \%)$ is increased significantly because the PREICE effect is not included to hinder the homogeneous freezing. The occurrence frequency of $N_{\mathrm{i}}>100 \mathrm{~L}^{-1}$ from Nofhom $(\sim 22 \%)$ is also larger than that from Preice because homogeneous nucleation takes place in the whole area of the cirrus clouds in Nofhom. We note that the observed $N_{\mathrm{i}}$ is from in situ aircraft measurements, while the modeled $N_{\mathrm{i}}$ represents the averages over the whole area of the cirrus clouds within a model grid cell $(\sim 100 \mathrm{~km})$. In addition, although measurements during the SPARTICUS campaign have significantly reduced the shattering of ice crystals, it is unclear whether the very high $\mathrm{Ni}\left(>1000 \mathrm{~L}^{-1}\right)$ is caused by the shattering artifact. These modeling and measurement issues need to be considered when comparing model results with observations.

The timescale of homogeneous freezing in a rising air parcel is a few minutes ( $140 \mathrm{~s}$ at $W=0.1 \mathrm{~m} \mathrm{~s}^{-1}$; Spichtinger and Krämer, 2013). It is still a challenge to sample the homogeneous freezing process and to grasp the fraction of cirrus clouds experiencing the homogeneous freezing in the real atmosphere. Thus, we cannot directly compare modeled $f_{\text {hom }}$ with observations. Modeled $f_{\text {hom }}$ from Sect. 2 peaks at the tropical tropopause layer (TTL) due to higher $W_{\text {sub }}$ and lower $T$, with a maximum of $\sim 10-20 \%$. It is $\sim 5 \%$ at mid-latitudes and even smaller at high latitudes. Here, we make a preliminary analysis of observed upcoming homogeneous nucleation events from the Tropical Composition, Cloud and Climate Coupling Experiment (TC4) and the Midlatitude Airborne Cirrus Properties Experiment (MACPEX). An observed upcoming homogeneous nucleation event is de-
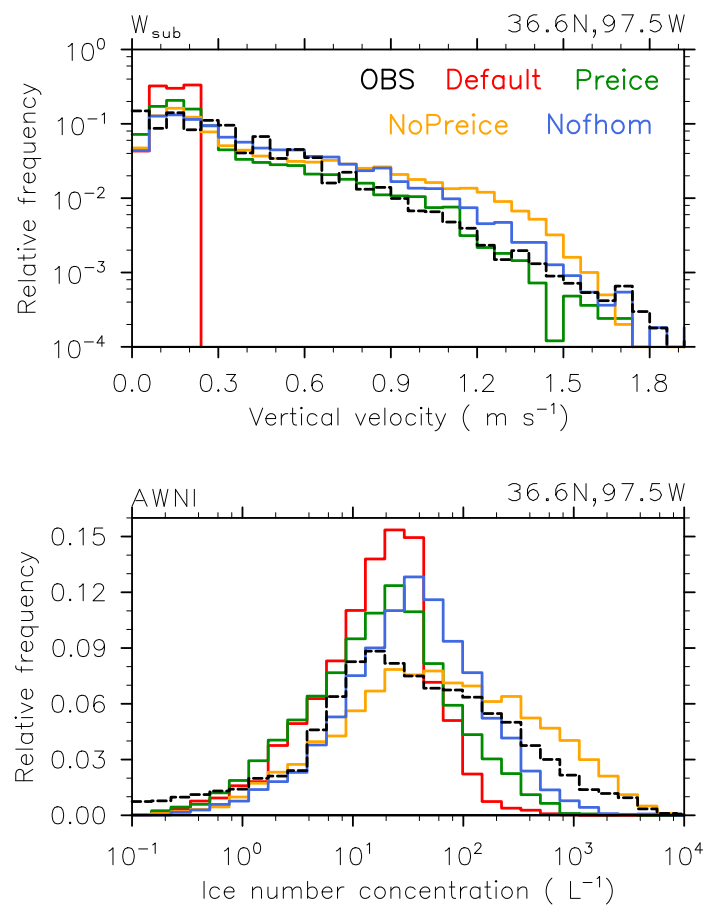

Figure 3. Probability distribution frequency of sub-grid updraft velocity ( $W_{\text {sub }}$, upper panel) and in-cloud ice number concentration $\left(N_{\mathrm{i}}\right.$, lower panel) for Default, Preice, Nofhom and NoPreice experiments. Black dashed line refers to aircraft measurements from the SPARTICUS campaign. The observed $W_{\text {sub }}$ data were averaged over $50 \mathrm{~km} \times 50 \mathrm{~km}$ grid (Zhang et al., 2013b). Model results are sampled over the field measurement site every $3 \mathrm{~h}$.

fined as an event when $S_{\mathrm{i}}$ in a rising air parcel will reach $S_{\text {hom }}$ within the timescale of $1 \mathrm{~min}$. The timescale of homogeneous freezing is assumed to be $1 \mathrm{~min}$ because the observed upcoming homogeneous nucleation events usually go with high $W\left(>0.5 \mathrm{~m} \mathrm{~s}^{-1}\right)$. The occurrence frequency of upcoming homogeneous nucleation events is 31 out of 8489 $\left(3.7 \times 10^{-3}\right)$ and 10 out of $27017\left(3.7 \times 10^{-4}\right)$ from TC4 and MACPEX in-cloud observation data, respectively. In other words, $3.7 \times 10^{-3}$ (TC4) and $3.7 \times 10^{-4}$ (MACPEX) of cirrus clouds will go through homogeneous nucleation in $1 \mathrm{~min}$. With a timescale of $30 \mathrm{~min}$ (the model time step), the observed $f_{\text {hom }}$ would be $\sim 10$ and $\sim 1 \%$ over TC 4 and MACPEX, respectively. Here, we assume the fraction of cirrus clouds that go through homogeneous nucleation is constant in every minute. Modeled $f_{\text {hom }}$ is close to this observational analysis in the tropical regions. Both modeling and observational analyses suggest that $f_{\text {hom }}$ in the tropical regions is larger than that in mid-latitudes. Diao et al. (2013) analyzed the evolution of ice crystals based on in situ observations over North America. They found that ice crystal formation/growth is $\sim 20 \%$ of total analyzed samples. This value is not limited to the homogeneous freezing events, but includes the heterogeneous freezing and ice crystal growth 


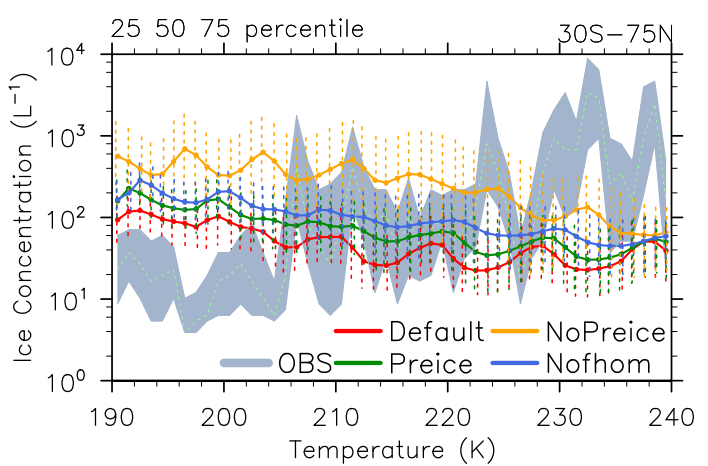

Figure 4. In-cloud ice crystal number concentration $\left(N_{\mathrm{i}}, \mathrm{L}^{-1}\right)$ versus temperature for Default, Preice, Nofhom and NoPreice experiments. Model results are sampled every $3 \mathrm{~h}$ over tropical, midlatitude and Arctic regions including the observation locations reported in Krämer et al. (2009). The 50th (solid line), 25th and 75th percentiles (error bar) are shown for each $1 \mathrm{~K}$ temperature bin. The gray color indicates observations between 25 th and 75 th percentiles.

events. So it is reasonable to assume that $f_{\text {hom }}$ is less than $20 \%$.

Figure 4 compares the variation of modeled $N_{\mathrm{i}}$ versus temperature against that observed in Krämer et al. (2009) who collected an extensive aircraft data set in the temperature range of $183-250 \mathrm{~K}$. Note that, these observations might be influenced by shattering of ice crystals, especially for warm cirrus clouds with relative larger ice crystals (Field et al., 2006). Therefore, for the following comparison, we should keep in mind that the observed $N_{\mathrm{i}}$ might be overestimated in warm cirrus clouds. The most distinct feature of this figure is that modeled $N_{\mathrm{i}}$ tends to increase with decreasing temperature for the whole temperature range. This temperature variation is caused by the homogeneous nucleation mechanism. Based on the same sulfate particles, homogeneous nucleation tends to produce more ice crystals at lower temperature (Liu and Penner, 2005). It is obvious that the modeled trend of increasing $N_{\mathrm{i}}$ with decreasing temperature is contrary to what is observed. At temperature below $205 \mathrm{~K}$, observed $N_{\mathrm{i}}$ is in the range of $10-80 \mathrm{~L}^{-1}$, whereas modeled $N_{\mathrm{i}}$ is in the range of $50-2000 \mathrm{~L}^{-1}$. Liu et al. (2012a) gave a possible explanation for this: heterogeneous nucleation could be the primary nucleation mechanism under these very low temperatures (i.e., near TTL) because homogeneous freezing might be suppressed by aerosols rich with organic matter (Murray, 2008; Krämer et al., 2009; Jensen et al., 2010; Murray et al., 2010). Barahona and Nenes (2011) suggested that smallscale temperature fluctuations could make cirrus clouds reside in a dynamic equilibrium state with sustained levels of low $N_{\mathrm{i}}$ consistent with cirrus characteristics observed at TTL. Furthermore, Spichtinger and Krämer (2013) found that ice crystal production via homogeneous nucleation could be limited by high frequency gravity waves. However, these aerosol and dynamical characteristics are currently not accounted for in the model. In the temperature range of $205-230 \mathrm{~K}$, modeled $N_{\mathrm{i}}$ is close to the observed values. The $N_{\mathrm{i}}$ from Preice is higher than that in Default, and agrees better with observations. The main reason is that the two unphysical limits used for reducing the ice number concentrations are removed (see also the PDF of $N_{\mathrm{i}}$ in Fig. 3, lower panel). In both NoPreice and Nofhom, $N_{\mathrm{i}}$ is remarkably larger than in Preice. Compared to Default, Preice and Nofhom predict higher $N_{\mathrm{i}}$ and show better agreement with observations in this temperature range. As discussed above, the main reason is that the two unphysical limits are removed.

The $N_{\mathrm{i}}$ differences between the default and updated nucleation schemes will affect modeled cloud radiative forcings. Figure 5 shows the annual and zonal means of longwave and shortwave cloud forcing (LWCF, SWCF), columnintegrated cloud ice number concentration (CDNUMI) and ice water path (IWP). Modeled CDNUMI from the NoPreice experiment is significantly higher than those from other experiments. As a result, higher IWP is shown in NoPreice. Compared to Preice, Nofhom also produces more CDNUMI and thus higher IWP. Thus, NoPreice predicts much stronger LWCF than other experiments, which is larger than observations in the tropical regions. LWCFs from Default, Preice and Nofhom agree with observations in the tropical regions, but are underestimated at mid- and high latitudes. In all experiments, modeled SWCFs agree with the observations at mid- and high latitudes, but are overestimated (more negative) in the tropical regions, especially for the NoPreice. Overall, there is no remarkable difference between the Default and Preice in-cloud radiative forcings (both LWCF and SWCF) because the difference in CDNUMI is relatively small.

Table 2 gives global and annual means of cloud and radiative flux variables from present-day simulations in Table 1 and comparisons with observations. Compared to the Default, CDNUMI from Preice, Nofhom and NoPreice increases by 40,133 , and $1130 \%$, respectively. Because cirrus clouds can heat the atmosphere by absorbing and reemitting the long-wave terrestrial radiation (Liou, 1986), the increase in CDNUMI can lead to the increase of atmospheric stability and the weakening of convection, such as the fast atmospheric response discussed in Andrews et al. (2010). Thus, convective precipitation rates (PRECC) from Preice, Nofhom and NoPreice are reduced compared to Default, especially for the NoPreice. Large-scale precipitation rates (PRECL) from Default, Preice, Nofhom and NoPreice are all close to each other (ranging from 1.04 to $1.05 \mathrm{~mm} \mathrm{day}^{-1}$ ). Compared to Default, IWP from Preice, Nofhom and NoPreice increases by 1.23, 3.18 and $7.96 \mathrm{~g} \mathrm{~m}^{-2}$, respectively. The reason is that higher ice number concentrations in these experiments lead to smaller ice crystal sizes and thus less sedimentation losses of ice water mass. In accordance with the increased ice water mass, high cloud fractions (CLDHGH) are also increased in these experiments. Liquid water path (LWP) and column-integrated 
Table 2. Global annual mean results from present-day simulations and observations. Shown are total cloud fraction (CLDTOT, \%) and high cloud fraction (CLDHGH, \%) compared to ISCCP data (Rossow and Schiffer, 1999), MODIS data (Platnick et al., 2003) and HIRS data (Wylie et al., 2005); shortwave cloud forcing (SWCF, $\mathrm{W} \mathrm{m}^{-2}$ ), long-wave cloud forcing (LWCF, $\mathrm{W} \mathrm{m}^{-2}$ ), whole-sky shortwave (FSNT, $\mathrm{W} \mathrm{m}^{-2}$ ) and long-wave (FLNT, $\mathrm{W} \mathrm{m}^{-2}$ ) net radiative fluxes at the top of the atmosphere, clear-sky shortwave (FSNTC, $\mathrm{W} \mathrm{m}^{-2}$ ) and longwave (FLNTC, $\mathrm{W} \mathrm{m}^{-2}$ ) radiative fluxes at the top of the atmosphere compared to ERBE data (Kiehl and Trenberth, 1997) and CERES data (Loeb et al. 2009); liquid water path (LWP; $\mathrm{g} \mathrm{m}^{-2}$ ) compared to SSM/I oceans data (Greenwald et al., 1993; Weng and Grody, 1994) and ISCCP data (Han et al., 1994); ice water path (IWP, $\mathrm{g} \mathrm{m}^{-2}$ ) compared to CloudSat data (Li et al., 2012); column-integrated grid-mean cloud droplet number concentration (CDNUMC, $10^{10} \mathrm{~m}^{-2}$ ) compared to MODIS data (Table 4 in Barahona et al., 2014); column-integrated grid-mean ice crystal number concentration (CDNUMI, $10^{6} \mathrm{~m}^{-2}$ ), convective (PRECC, $\mathrm{mm} \mathrm{d}^{-1}$ ) and large-scale (PRECL, mm $\mathrm{d}^{-1}$ ) and total precipitation rate (PRECT, $\mathrm{mm} \mathrm{d}^{-1}$ ) compared to Global Precipitation Climatology Project data set (Adler et al., 2003).

\begin{tabular}{|c|c|c|c|c|c|c|c|c|c|}
\hline & Default & Preice & Nofhom & NoPreice & PreiceBN & NoPreiceBN & PreiceKL & NoPreiceKL & OBS \\
\hline CLDTOT & 62.52 & 63.01 & 64.37 & 67.95 & 63.45 & 67.30 & 63.49 & 68.92 & $62-75$ \\
\hline CLDHGH & 36.34 & 37.26 & 38.92 & 44.12 & 37.95 & 43.55 & 38.01 & 45.89 & $21-33$ \\
\hline SWCF & -50.25 & -51.52 & -53.96 & -62.67 & -51.30 & -59.07 & -51.38 & -63.15 & $-(46-53)$ \\
\hline LWCF & 22.42 & 23.65 & 27.12 & 34.81 & 23.38 & 31.42 & 23.25 & 35.85 & 27-31 \\
\hline FSNT & 237.38 & 236.08 & 233.66 & 225.16 & 236.33 & 228.71 & 236.21 & 224.74 & 234-242 \\
\hline FLNT & -236.26 & -234.88 & -231.44 & -222.49 & -235.24 & -226.38 & -235.32 & -221.50 & $-(234-240)$ \\
\hline FSNTC & 287.67 & 287.63 & 287.67 & 287.88 & 287.66 & 287.83 & 287.62 & 287.94 & 287-288 \\
\hline FLNTC & -258.68 & -258.53 & -258.57 & -257.31 & -258.62 & -257.80 & -258.57 & -257.34 & $-(265-269)$ \\
\hline LWP & 43.62 & 43.90 & 44.60 & 46.72 & 43.84 & 45.88 & 43.94 & 46.78 & $50-87$ \\
\hline IWP & 16.37 & 17.60 & 19.55 & 24.33 & 17.09 & 21.09 & 17.01 & 23.87 & 25.8 \\
\hline CDNUMC & 1.37 & 1.39 & 1.42 & 1.53 & 1.39 & 1.49 & 1.40 & 1.53 & 1.96 \\
\hline CDNUMI & 83.20 & 119.32 & 193.30 & 1021.05 & 116.19 & 702.59 & 119.43 & 1267.13 & \\
\hline PRECC & 2.01 & 1.97 & 1.90 & 1.71 & 1.98 & 1.78 & 1.98 & 1.69 & \\
\hline PRECL & 1.04 & 1.05 & 1.05 & 1.05 & 1.05 & 1.06 & 1.05 & 1.05 & \\
\hline PRECT & 3.05 & 3.02 & 2.95 & 2.75 & 3.02 & 2.84 & 3.03 & 2.74 & 2.68 \\
\hline
\end{tabular}
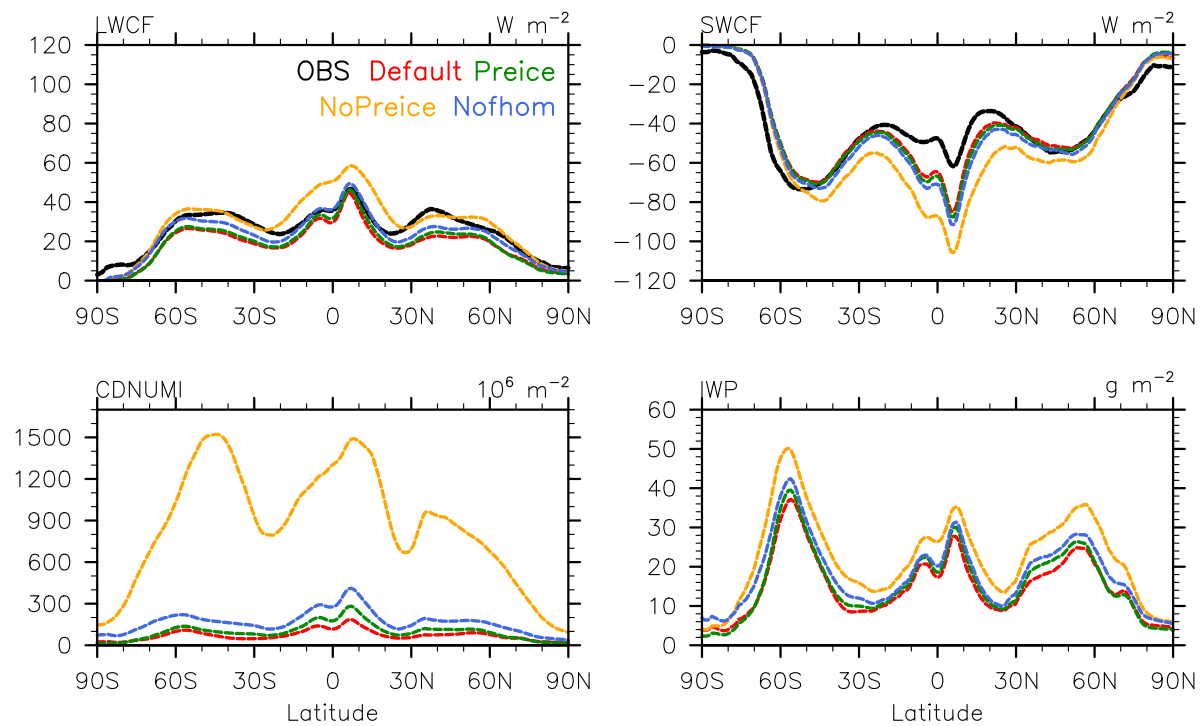

Figure 5. Annual and zonal mean distributions of long-wave and shortwave cloud forcing (LWCF, SWCF), column cloud ice number concentration (CDNUMI) and ice water path (IWP). Black solid line refers to CERES data for cloud forcing (Wielicki et al., 1996). Units are shown in the upper right corner.

droplet number concentration (CDNUMC) from the three experiments are also increased with increasing CDNUMI. This might be a result of increased atmospheric stability and weakened convection. Obviously, SWCF and LWCF from Preice, Nofhom and NoPreice become stronger due to the in- creases in LWP, IWP, CDNUMC and CDNUMI as compared to the Default. Changes in SWCF and LWCF between the Default and Preice are moderate $\left(-1.27 \mathrm{~W} \mathrm{~m}^{-2}\right.$ in SWCF, $1.23 \mathrm{~W} \mathrm{~m}^{-2}$ in LWCF). Overall, global annual mean results 
from both Default and Preice show generally good agreements with observations.

The estimated anthropogenic aerosol effects are given in Table 3. The more representative method suggested by Ghan (2013) is used to estimate aerosol effects on cloud radiative forcings. Cloud radiative forcings marked with an asterisk are diagnosed from the whole-sky and clear-sky topof-atmosphere radiative fluxes with aerosol scattering and absorption neglected. $\Delta$ indicates a change between presentday (the year 2000) and pre-industrial times (the year 1850) with the only change in aerosol and precursor gas emissions. $\triangle$ CDNUMI in Preice is larger than in Default due to the use of all sulfate number concentration in the Aitken mode. The differences in cloud forcings $\left(\triangle \mathrm{SWCF}^{*}\right.$ and $\left.\triangle \mathrm{LWCF}^{*}\right)$ between Preice and Default are less than 1 standard deviation $\left(0.19 \mathrm{~W} \mathrm{~m}^{-2}\right.$ for $\triangle \mathrm{SWCF}^{*}$ and $0.13 \mathrm{~W} \mathrm{~m}^{-2}$ for $\left.\triangle \mathrm{LWCF}^{*}\right)$ calculated from the difference of each of 5 years. $\triangle$ SWCF $^{*}$ and $\triangle \mathrm{LWCF}^{*}$ in Nofhom are both a little stronger than in Preice. NoPreice gives the strongest changes in cloud forcings $\left(\triangle \mathrm{SWCF}^{*}\right.$ and $\left.\triangle \mathrm{LWCF}^{*}\right)$ and in cloud water paths ( $\triangle$ LWP and $\triangle \mathrm{IWP}$ ), because $\triangle \mathrm{CDNUMI}$ is largest in this experiment. $\triangle$ PRECC in Default, Preice and Nofhom are negligibly small. Overall, the difference in the simulated anthropogenic aerosol indirect forcing $\left(\Delta \mathrm{CF}^{*}\right)$ between the Default and Preice is small $\left(\sim 0.1 \mathrm{~W} \mathrm{~m}^{-2}\right)$.

\section{PREICE effect and sensitivity to different ice nucleation parameterizations}

In this section we analyze the effect of PREICE and its sensitivity to different ice nucleation parameterizations. Considering the PREICE effect, the effective updraft velocity, $W_{\text {eff }}\left(W_{\text {eff }}=W_{\text {sub }}-W_{\text {i, pre }}\right)$, is used to drive the ice nucleation parameterization. Figure 6 shows the PDF of $W_{\text {sub }}, W_{\text {eff }}$ and $W_{\mathrm{i} \text {,pre }}$ from homogeneous ice nucleation occurrence events in Preice. Results from PreiceBN and PreiceKL have similar patterns to Preice (not shown). For ice nucleation occurrence events ( $\left.W_{\text {eff }}>0\right), W_{\mathrm{i} \text {,pre }}$ is mainly distributed in the range of $0-0.1 \mathrm{~m} \mathrm{~s}^{-1}$. This indicates that ice nucleation usually happens at low PREICE number concentrations $\left(<50 \mathrm{~L}^{-1}\right)$. Different from the PDF pattern of model diagnosed $W_{\text {sub }}$ (Fig. 3, upper panel) which includes all samples, the most frequently sampled $W_{\text {sub }}$ with occurrence of ice nucleation events is in the range of $0.1-0.4 \mathrm{~m} \mathrm{~s}^{-1}$ because $W_{\text {sub }}$ must be larger than $W_{\mathrm{i}, \text { pre }} . W_{\text {eff }}$ is mainly distributed in a range of $0-0.3 \mathrm{~m} \mathrm{~s}^{-1}$, and rarely larger than $1.0 \mathrm{~m} \mathrm{~s}^{-1}$. The comparison between $W_{\text {eff }}$ and $W_{\text {sub }}$ indicates that PREICE reduces not only the occurrence frequency of homogeneous nucleation but also the number density of nucleated ice crystals from homogeneous nucleation.

Figure 7 shows the annual zonal mean $N_{\mathrm{i}}$ from NoPreice and Preice. NoPreiceBN, PreiceBN, NoPreiceKL and PreiceKL experiments are also analyzed, but not shown here, because the effect of PREICE in experiments using $\mathrm{BN}$ and

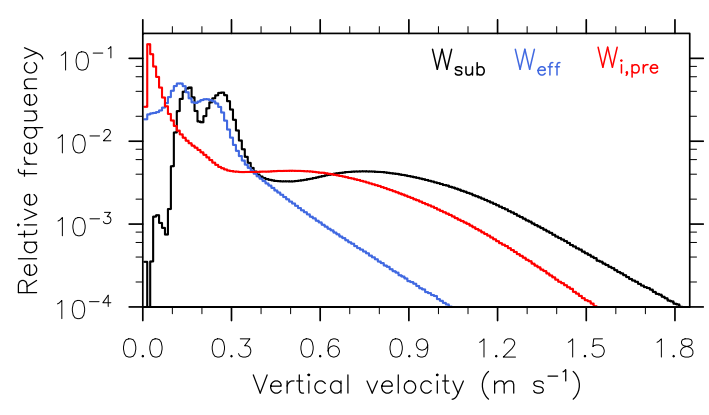

Figure 6. Probability distribution frequency (PDF) of sub-grid updraft velocity ( $W_{\text {sub }}$, black), effective updraft velocity ( $W_{\text {eff }}$, blue) and vertical velocity reduction caused by PREICE $\left(W_{i, p r e}\right.$, red) from the Preice experiment. Model results are sampled every $3 \mathrm{~h}$. Only homogeneous ice nucleation occurrence events $\left(W_{\text {eff }}>0\right)$ are analyzed.

KL parameterizations are similar to that using the LP parameterization. Without the influence of Preice, $N_{\mathrm{i}}$ is higher than $500 \mathrm{~L}^{-1}$ in the upper troposphere, and even higher $\left(>2000 \mathrm{~L}^{-1}\right)$ at mid- and high latitudes of the Southern Hemisphere (SH). After considering the PREICE effects, $N_{\mathrm{i}}$ is significantly reduced, especially at mid- and high latitudes in the upper troposphere (by a factor of $\sim 10$ ). Global annual mean results show that CDNUMI from simulations using LP, BN and KL parameterizations, is reduced by a factor of 6-11 (Table 2) after the PREICE effect is considered. Compared to the distribution pattern from NoPreice, $N_{\mathrm{i}}$ from Preice is higher in the tropical tropopause region rather than in the SH upper troposphere. It seems that the influence of PREICE is relatively weaker in the tropical tropopause due to low $T$ and high $W_{\text {sub }}$ there (not shown).

Because of the large difference in $N_{\mathrm{i}}$ between experiments with and without the effects of PREICE, there must be consequent differences in cloud forcings and precipitation as explained above. Compared to experiments with the PREICE effect, PRECC (precipitation) from NoPreice, NoPreiceBN and NoPreiceKL are reduced by 13, 10 and $15 \%$, respectively (Table 2). The LWCF changes range from 8.0 to $12.6 \mathrm{~W} \mathrm{~m}^{-2}$ in simulations using the $\mathrm{LP}, \mathrm{BN}$ and $\mathrm{KL}$ parameterizations. SWCF changes have similar magnitude but with the opposite sign. Barahona et al. (2014) studied the effect of PREICE using GEOS5 with the BN parameterization. Change in LWCF and SWCF due to PREICE is 5 and $4 \mathrm{~W} \mathrm{~m}^{-2}$, respectively. We note that heterogeneous ice nucleation in GEOS5 includes the immersion nucleation and deposition nucleation on dust, black carbon and soluble organics. In their study, the global mean $N_{\mathrm{i}}$ from the heterogeneous nucleation and its contribution to total $N_{\mathrm{i}}$ are $\sim 22 \mathrm{~L}^{-1}$ and $\sim 30 \%$, respectively (Fig. 7 in Barahona et al., 2014). In our study using the modified CAM5.3 with the BN parameterization, the $N_{\mathrm{i}}$ from the heterogeneous nucleation and its contribution to total $N_{\mathrm{i}}$ are $5.1 \mathrm{~L}^{-1}$ and $9.4 \%$, respectively. The number concentration 
Table 3. Global annual mean variable changes (present-day minus pre-industrial times). Illustrated are changes in net cloud forcing $\left(\Delta \mathrm{CF}^{*}, \mathrm{~W} \mathrm{~m}^{-2}\right)$ as well as the long-wave $\left(\Delta \mathrm{LWCF}^{*}, \mathrm{~W} \mathrm{~m}^{-2}\right)$ and shortwave $\left(\triangle \mathrm{SWCF}^{*}, \mathrm{~W} \mathrm{~m}^{-2}\right)$ components; the changes in convective $\left(\triangle \mathrm{PRECC}, \mathrm{mm} \mathrm{d}^{-1}\right)$, large-scale $\left(\triangle \mathrm{PRECL}, \mathrm{mm} \mathrm{d}^{-1}\right)$ and total precipitation rate $\left(\triangle \mathrm{PRECT}, \mathrm{mm} \mathrm{d}^{-1}\right)$; the change in total cloud fraction ( $\triangle$ CLDTOT, $\%$ ), high cloud fraction $(\triangle \mathrm{CLDHGH}, \%)$, liquid water path $\left(\Delta \mathrm{LWP}, \mathrm{g} \mathrm{m}^{-2}\right)$, ice water path $\left(\Delta \mathrm{IWP}, \mathrm{g} \mathrm{m}^{-2}\right)$; and column droplet number concentration ( $\triangle \mathrm{CDNUMC}, 10^{10} \mathrm{~m}^{-2}$ ) and column ice number concentration $\left(\triangle \mathrm{CDNUMI}, 10^{6} \mathrm{~m}^{-2}\right.$ ).

\begin{tabular}{lrrrrrrrr}
\hline & Default & Preice & Nofhom & NoPreice & PreiceBN & NoPreiceBN & PreiceKL & NoPreiceKL \\
\hline$\Delta$ CF $^{*}$ & -1.44 & -1.55 & -1.60 & -2.14 & -1.47 & -1.88 & -1.64 & -2.23 \\
$\Delta$ SWCF $^{*}$ & -1.95 & -2.01 & -2.13 & -4.51 & -1.86 & -3.58 & -1.88 & -3.94 \\
$\Delta$ LWCF & 0.51 & 0.46 & 0.53 & 2.37 & 0.39 & 1.70 & 0.24 & 1.71 \\
$\Delta$ PRECC & 0 & 0 & 0 & -0.03 & -0.01 & -0.02 & 0 & -0.02 \\
$\Delta$ PRECL & -0.0 & -0.01 & -0.01 & -0.02 & -0.01 & -0.02 & -0.01 & -0.02 \\
$\Delta$ PRECT & -0.01 & -0.01 & -0.01 & -0.05 & -0.02 & -0.04 & -0.01 & -0.04 \\
$\Delta$ CLDTOT & 0.22 & 0.28 & 0.40 & 0.84 & 0.32 & 0.70 & 0.19 & 0.74 \\
$\Delta$ CLDHGH & 0.02 & 0.20 & 0.24 & 0.95 & 0.12 & 0.73 & 0.01 & 0.62 \\
$\Delta$ LWP & 3.83 & 3.59 & 3.77 & 5.73 & 3.40 & 4.33 & 3.66 & 4.56 \\
$\Delta$ IWP & 0.12 & 0.12 & 0.14 & 1.21 & 0.03 & 0.62 & 0.01 & 0.60 \\
$\Delta$ CDNUMC & 0.38 & 0.38 & 0.40 & 0.47 & 0.38 & 0.44 & 0.39 & 0.45 \\
$\Delta$ CDNUMI & 5.60 & 8.46 & 13.10 & 327.38 & 5.62 & 116.49 & 3.24 & 225.42 \\
\hline
\end{tabular}
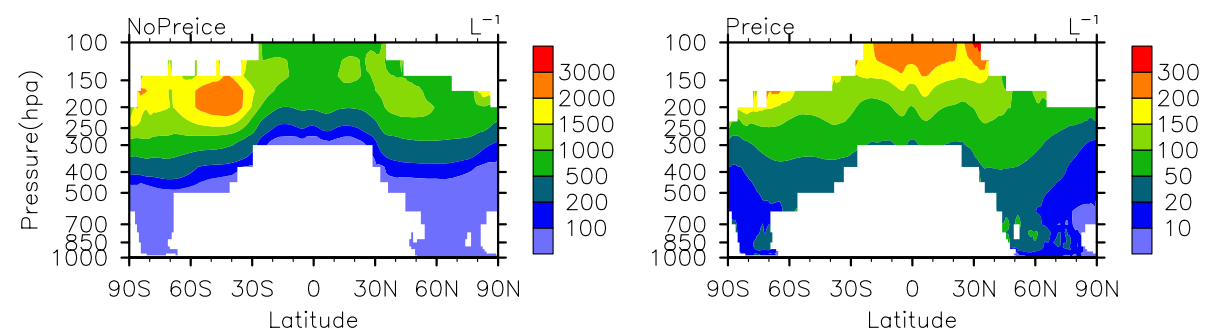

Figure 7. Annual zonal mean in-cloud ice crystal number concentration $\left(N_{\mathrm{i}}, \mathrm{L}^{-1}\right)$ from NoPreice (left) and Preice (right) experiments. Note the different color bars. Results are sampled from model grids where annual mean occurrence frequency of ice nucleation events is greater than 0.001 .

of heterogeneous IN from CAM5.3 is significantly lower than that from GEOS5. As a result, in CAM5.3 there are fewer IN competing with the homogeneous ice nucleation and PREICE has a larger impact. This might be the main reason why the PREICE effect in CAM5.3 with the BN parameterization is stronger than that in GEOS5. In ECHAM5 with the KL parameterization, changes in LWCF and SWCF are 1.5 and $0.95 \mathrm{~W} \mathrm{~m}^{-2}$, respectively, when heterogeneous nucleation and PREICE (during ice nucleation process) are taken into account (Kuebbeler et al., 2014). In the study of Kuebbeler et al. (2014), both deposition nucleation on pure dust and immersion nucleation on coated dust were included. The number concentration of heterogeneous IN (including the deposition and immersion modes) ranges between 0.1 and $10 \mathrm{~L}^{-1}$ (Fig. 2 in Kuebbeler et al., 2014). This IN number concentration is similar to ours. However, both sulfate number concentration and total $N_{\mathrm{i}}$ in Kuebbeler et al. (2014) are much higher than ours (by a factor of $\sim 5-20$ in most regions). We note that in ECHAM5 ice nucleation process requires that the model grid is supersaturated with respect to ice (i.e., $\mathrm{RH}_{\mathrm{i}}>100 \%$ ), and the depositional growth of ice crystals is treated based on the model grid-mean $\mathrm{RH}_{\mathrm{i}}$. If a model grid is supersaturated and a sufficient number of PREICE is present, the depositional growth of the PREICE treated in the cirrus cloud microphysics scheme will remove the supersaturation in the grid, hinder the subsequent ice nucleation and significantly reduce the occurrence frequency of ice nucleation events (Kuebbeler et al., 2014). Thus, the effect of PREICE on the subsequent ice nucleation, which is represented by reducing the updraft velocity, is much weakened in ECHAM5.

Table 4 gives the influence of PREICE on the relative contribution of homogeneous versus heterogeneous nucleation to the total ice number concentration in cirrus clouds. The contributions of heterogeneous nucleation from experiments without the effects of PREICE are less than $1 \%$. After considering the PREICE effects, the contribution of heterogeneous nucleation from Preice, PreiceBN and PreiceKL is increased to $17.6,9.4$ and $8.9 \%$, respectively. The reason is that when PREICE is taken into account, the newly formed ice crystal number concentration from homogeneous nucleation is significantly reduced (by a factor of $\sim 10$, not shown), whereas the ice crystal number concentration from heterogeneous nucleation is slightly decreased. This indicates that 
Table 4. All percentage contributions from heterogeneous ice nucleation to total ice crystal number concentration (in unit of \%) within different ranges of dust number concentration for all present-day simulations. Model results are sampled every $3 \mathrm{~h}$. Only ice nucleation occurrence events are analyzed.

\begin{tabular}{lrrrrrrrr}
\hline Dust range & Default & Preice & Nofhom & NoPreice & PreiceBN & NoPreiceBN & PreiceKL & NoPreiceKL \\
\hline $1-10 \mathrm{~L}^{-1}$ & 6.8 & 5.7 & 2.1 & 0.1 & 3.3 & 0.3 & 3.4 & 0.1 \\
$10-100 \mathrm{~L}^{-1}$ & 62.1 & 41.2 & 21.0 & 1.4 & 34.8 & 3.9 & 33.8 & 1.9 \\
$>100 \mathrm{~L}^{-1}$ & 99.5 & 89.8 & 78.0 & 10.9 & 92.2 & 39.2 & 93.0 & 25.8 \\
All & 27.9 & 17.6 & 6.7 & 0.5 & 9.4 & 1.0 & 8.9 & 0.5 \\
\hline
\end{tabular}

the PREICE effects can significantly change the relative contribution of homogeneous versus heterogeneous nucleation to cirrus formation, especially at higher dust number concentrations (Table 4).

\section{Comparison between different ice nucleation parameterizations}

In this section we focus on the comparison between Default, Preice, PreiceBN and PreiceKL experiments. Since the two unphysical limits are removed in Preice, PreiceBN and PreiceKL, $N_{\mathrm{i}}$ from these experiments is slightly larger than that from Default (Fig. 8, left). Although the parameterization details are very different between LP, BN and KL, the simulated $N_{\mathrm{i}}$ has a very similar pattern in these simulations under similar meteorological conditions $\left(W, T, \mathrm{RH}_{\mathrm{i}}\right)$ and aerosol distributions. One distinct feature of $N_{\mathrm{i}}$ distribution patterns from these experiments is that $N_{\mathrm{i}}$ reduces towards lower altitudes. This is caused by the homogeneous nucleation rate reduction with increasing temperature (Koop, 2004). The global and annual mean CDNUMIs from Preice, PreiceBN and PreiceKL are close to each other (ranging from $116 \times 10^{6}$ to $119 \times 10^{6} \mathrm{~m}^{-2}$; Table 2). However, differences in the global and annual mean percentage contribution from heterogeneous ice nucleation among Preice (17.6\%), PreiceBN (9.4\%) and PreiceKL (8.9\%) experiments are obvious (Table 4). Overall, the heterogeneous nucleation contributions from Preice, PreiceBN and PreiceKL have similar distribution patterns (Fig. 8, right panels). Contribution from the heterogeneous nucleation is less than $10 \%$ in the tropical upper troposphere and in the SH. In other words, homogeneous nucleation is the dominant contributor there. In the tropical lower troposphere and in the Northern Hemisphere (NH), heterogeneous nucleation became more important due to higher dust number concentrations. The study of Liu et al. (2012a) showed that difference in heterogeneous nucleation contribution between simulations using the LP parameterization and the $\mathrm{BN}$ parameterization is obvious, especially in the NH. Note that the empirical parameterization by Phillips et al. (2008) is used to describe the heterogeneous nucleation on dust particles for the $\mathrm{BN}$ parameterization in the work of Liu et al. (2012a), whereas the nucleation spectra based on CNT (without the upper limit of dust activated fraction) is used in our study. Kuebbeler et al. (2014) also studied the contribution from heterogeneous nucleation using the ECHAM5 model with the KL parameterization. They found that heterogeneous nucleation contributes the largest in the tropical troposphere and in the Arctic. At the midand high latitudes in the $\mathrm{NH}$, their model results show that the contribution from heterogeneous nucleation is less than $1 \%$, whereas our model results show that the contribution from heterogeneous nucleation is larger than $10 \%$. One important difference between the KL parameterization used in our study and the KL parameterization used by Kuebbeler et al. (2014) is that they modified the KL parameterization by including an upper limit of activated fraction of pure dust particles as a function of $S_{\mathrm{i}}$. This may cause the difference in the heterogeneous nucleation contribution between our and their studies.

Figure 9 shows the changes in annual and zonal mean LWCF, SWCF, CDNUMI and IWP between simulations using present-day and pre-industrial emissions. $\triangle \mathrm{CDNUMI}$ from all experiments is around zero in the SH because changes in sulfate and dust aerosol number densities that drive ice nucleation parameterizations are small. $\triangle \mathrm{CDNUMI}$ from the PreiceKL experiment is smaller between 30 and $60^{\circ} \mathrm{N}$ as compared to other experiments. In regions higher than $60^{\circ} \mathrm{N}$ or lower than $30^{\circ} \mathrm{N}$, all experiments are rather similar. The reason is that the ice crystal number concentration from homogeneous freezing is not sensitive to sulfate number concentrations in most cases in the KL parameterization, whereas it is more sensitive to sulfate number concentrations in the other two parameterizations. We note that Table 1 in Kärcher and Lohmann (2002a) showed that $N_{\mathrm{i}}$ from the KL parameterization became sensitive to sulfate number concentration under low temperature (200K) and high updraft velocity $\left(0.4,4 \mathrm{~m} \mathrm{~s}^{-1}\right)$. Thus, $\triangle \mathrm{CDNUMI}$ with the KL parameterization can reach $10 \times 10^{6} \mathrm{~m}^{-2}$ in the tropical regions due to low $T$ and high $W_{\text {sub }}$ there. $\triangle$ CDNUMI from the Preice experiment between 60 and $80^{\circ} \mathrm{N}$ (negative) has the opposite sign than the other experiments (positive). However, these changes are generally within the ranges of 2 standard deviations. Table 3 shows that the global mean $\triangle$ CDNUMI from PreiceKL $\left(3.24 \times 10^{6} \mathrm{~m}^{-2}\right)$ is less than those from Preice $\left(8.46 \times 10^{6} \mathrm{~m}^{-2}\right)$ and PreiceBN $\left(5.62 \times 10^{6} \mathrm{~m}^{-2}\right)$. Compared to $\triangle \mathrm{CDNUMI}$, the fluctuation 

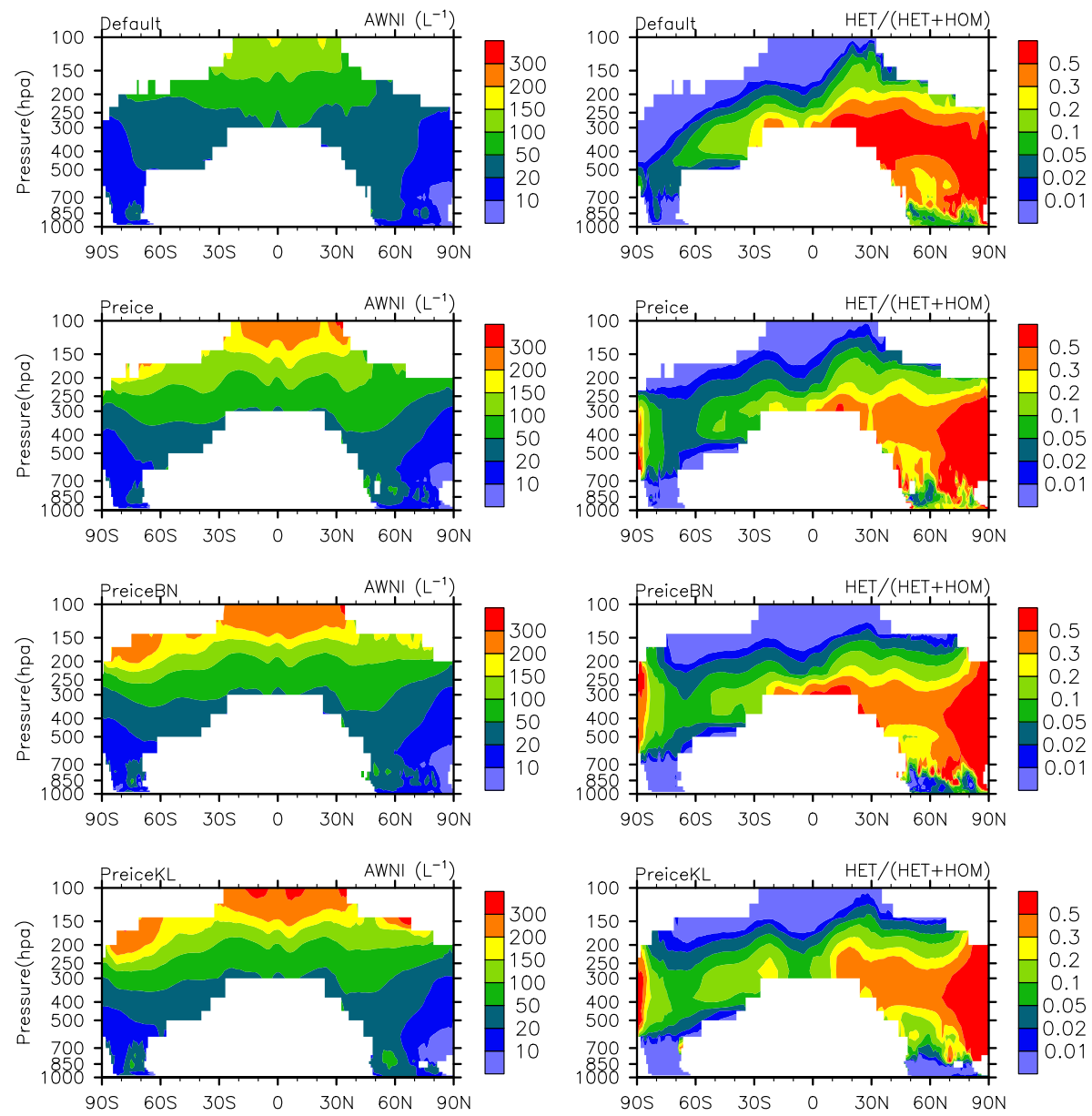

Figure 8. Same as Fig. 7, but for in-cloud ice crystal number concentration $\left(\mathrm{L}^{-1}\right.$, left) and percentage contribution from heterogeneous ice nucleation to total ice crystal number concentration (\%, right) from Default, Preice, PreiceBN and PreiceKL experiments.

of $\triangle \mathrm{IWP}$ is more complicated because many other microphysical processes (especially in mixed-phase clouds) can also impact $\triangle$ IWP. Furthermore, changes in cloud properties caused by the aerosol indirect effects may modulate the atmospheric circulation and water vapor transport, and then impact IWP in other regions. Changes in circulation would affect convection and the detrainment of ice crystals. This might explain why $\Delta$ IWP from all experiments are not statistically significant. Differences in global and annual mean $\triangle \mathrm{IWP}$ among these experiments are also remarkable. Global mean $\triangle$ IWP from Preice, PreiceBN and PreiceKL are $0.12,0.03$ and $0.01 \mathrm{~g} \mathrm{~m}^{-2}$, respectively (Table 3). $\triangle$ SWCF is mainly caused by aerosol indirect effects through warm clouds (Gettelman et al., 2012). Thus, patterns of $\triangle \mathrm{SWCF}$ with different ice nucleation parameterizations are similar, and not obviously correlated with $\triangle$ CDNUMI. Differences in global and annual mean $\triangle \mathrm{SWCF}^{*}$ among Preice $\left(-2.01 \mathrm{~W} \mathrm{~m}^{-2}\right)$, PreiceBN $\left(-1.86 \mathrm{~W} \mathrm{~m}^{-2}\right)$ and PreiceKL $\left(-1.88 \mathrm{~W} \mathrm{~m}^{-2}\right)$ are relatively small (Table 3). However, the patterns of $\triangle \mathrm{LWCF}$ are associated with those of $\triangle \mathrm{CDNUMI}$ for all experiments. For example, both $\triangle \mathrm{LWCF}$ and $\triangle$ CDNUMI from the PreiceKL experiment are negative at mid-latitudes in the NH. Table 3 shows that the global and annual mean $\triangle \mathrm{LWCF}^{*}$ is strongest in Preice $\left(0.46 \mathrm{~W} \mathrm{~m}^{-2}\right)$, slightly weaker in PreiceBN $\left(0.39 \mathrm{~W} \mathrm{~m}^{-2}\right)$ and weakest in PreiceKL $\left(0.24 \mathrm{~W} \mathrm{~m}^{-2}\right)$. This is consistent with the difference in $\triangle \mathrm{CDNUMI}$

\section{Conclusions}

One purpose of this study is to improve the representation of ice nucleation in CAM5.3. First, the PREICE effect is considered by reducing vertical velocity $\left(W_{\text {eff }}=W_{\text {sub }}-W_{\mathrm{i}, \text { pre }}\right)$, following the method of KL parameterization. Second, homogeneous freezing takes place spatially only in a portion of the cirrus cloud $\left(f_{\text {hom }}\right)$ rather than in the whole area of the cirrus cloud. Barahona et al. (2014) considered a similar factor that accounts for ice nucleation occurrence area within the grid cell in GEOS5 based on results from a parcel statistical ensemble model (Barahona and Nenes, 2011). In our study, $f_{\text {hom }}$ is calculated by introducing 

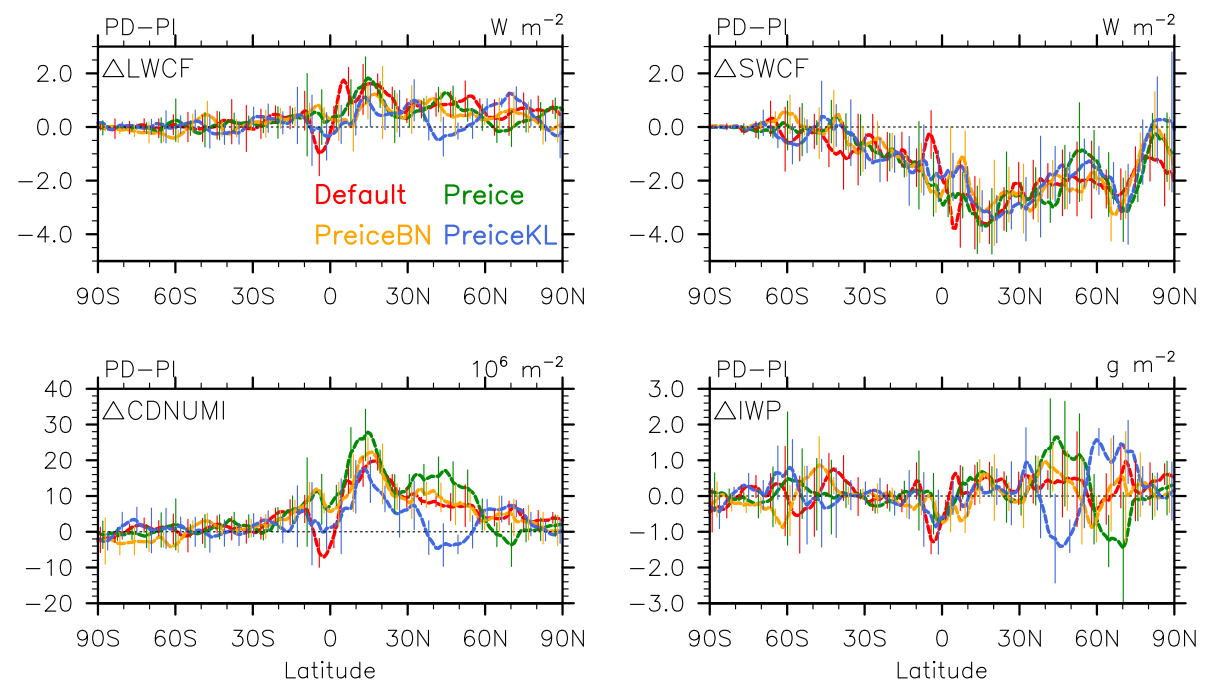

Figure 9. Changes (present-day minus pre-industrial times) in annual and zonal mean distributions of long-wave and shortwave cloud forcing (LWCF, SWCF), column cloud ice number concentration (CDNUMI) and ice water path (IWP) for Default, Preice, PreiceBN and PreiceKL experiments. The vertical bars overloading on solid lines indicate the ranges of 2 standard deviation calculated from the difference of each year for 5 years at different latitudes.

the PDF of in-cloud $S_{\mathrm{i}}$ based on the empirical analysis of Kärcher and Burkhardt (2008) and Hoyle et al. (2005). We note that only in-cloud $S_{\mathrm{i}}$ variability resulting from the sub-grid temperature fluctuation is taken into account in this study, whereas the sub-grid water vapor variability is neglected. Including the latter may lead to a much stronger effect and coupling between different nucleation events. The diagnosed $f_{\text {hom }}$ is in general less than $20 \%$, consistent with the work of Diao et al. (2013). We note that the uncertainty caused by $f_{\text {hom }}$ is moderate because the effect of $f_{\text {hom }}$ on ice number concentration is weaker than the PREICE effect. Finally, the two unphysical limits (the upper limit of $W_{\text {sub }}$ and the lower limit of Aitken mode sulfate aerosol size) used in the representation of ice nucleation in CAM5 are removed. Compared to observations, the probability distributions of ice number concentration and the diagnosed sub-grid updraft velocity are both improved with the updated treatment. The difference in cloud radiative forcings between the updated model and the default model is moderate $\left(-1.27 \mathrm{~W} \mathrm{~m}^{-2}\right.$ in SWCF, $1.23 \mathrm{~W} \mathrm{~m}^{-2}$ in LWCF).

The influence of PREICE on the relative contribution of homogeneous nucleation versus heterogeneous nucleation is studied using the updated CAM5.3 model. Model results show that $N_{\mathrm{i}}$ is significantly reduced because PREICE reduces the occurrence frequency of homogeneous nucleation, especially at mid- to high-latitudes in the upper troposphere (by a factor of $\sim 10$ ). As a result, the contribution of heterogeneous ice nucleation to cirrus ice crystal number increases considerably from 0.5 to $17.4 \%$ (Table 4 ).

The comparison between different ice nucleation parameterizations is also investigated using the updated CAM5.3 model. Both LP and BN parameterizations consider the PRE-
ICE effect based on the concept of the KL parameterization. The ice number distribution, the contribution from heterogeneous ice nucleation to the total ice nucleation and the influence of PREICE agree well among LP, BN and KL parameterizations in CAM5. However, compared to GEOS5 with the BN parameterization (Barahona et al., 2014) and ECHAM5 with the KL parameterization (Kuebbeler et al., 2014), BN and KL parameterizations in CAM5 give much stronger PREICE effects. In Kuebbeler et al. (2014), both the ice nucleation parameterization and the cloud microphysics scheme for the ice depositional growth include the PREICE effect. In the cloud microphysics scheme, the depositional growth of PREICE removes the supersaturation in the grid and hinders the subsequent ice nucleation. Thus, the effect of PREICE during the ice nucleation process, which is represented by reducing the updraft velocity, is weakened. GEOS5 considers the immersion and deposition ice nucleation on dust, black carbon and soluble organics (Barahona et al., 2014), while CAM5 only considers the immersion nucleation on coarse mode dust. As a result, heterogeneous IN number concentration and its contribution to total ice crystal number are much higher from GEOS5 $\left(\sim 22 \mathrm{~L}^{-1}\right.$ and $\sim 30 \%$, respectively, on the global annual mean) than those from CAM5 with the BN parameterization $\left(\sim 5.1 \mathrm{~L}^{-1}\right.$ and $9.4 \%$, respectively, on the global annual mean). This might explain the stronger PREICE effect from CAM5 with the $\mathrm{BN}$ parameterization. Therefore, the differences among this study (Barahona et al., 2014 and Kuebbeler et al., 2014) may be driven by differences in meteorological input parameters $\left(W, T, \mathrm{RH}_{\mathrm{i}}\right)$, the assumptions of aerosol inputs for ice nucleation parameterizations (e.g., immersion versus deposition freezing and aerosol characteristics), and the 
methodology of parameterization implementation in models, than ice nucleation parameterizations themselves. Another interesting finding is that $N_{\mathrm{i}}$ from the KL parameterization is not sensitive to sulfate number concentrations compared to LP and BN parameterizations. The global and annual mean change in column ice number concentration between presentday and pre-industrial time ( $\triangle$ CDNUMI) with the KL parameterization $\left(3.24 \times 10^{6} \mathrm{~m}^{-2}\right)$ is less that those with the LP parameterization $\left(8.46 \times 10^{6} \mathrm{~m}^{-2}\right)$ and the $\mathrm{BN}$ parameterization $\left(5.62 \times 10^{6} \mathrm{~m}^{-2}\right)$. The anthropogenic aerosols long-wave indirect forcing $\left(\triangle \mathrm{LWCF}^{*}\right)$ from the KL parameterization is $0.24 \mathrm{~W} \mathrm{~m}^{-2}$, smaller than that from the $\operatorname{LP}\left(0.46 \mathrm{~W} \mathrm{~m}^{-2}\right)$ and $\mathrm{BN}\left(0.39 \mathrm{~W} \mathrm{~m}^{-2}\right)$ parameterizations.

Acknowledgements. X. Liu and K. Zhang were supported by the Office of Science of US Department of Energy as part of the Earth System Modeling Program. X. Shi would like to acknowledge the support from the National Natural Science Foundation of China (grant no. 41205071). We would like to acknowledge the use of computational resources (ark:/85065/d7wd3xhc) at the NCAR-Wyoming Supercomputing Center provided by the National Science Foundation and the State of Wyoming, and supported by NCAR's Computational and Information Systems Laboratory. PNNL is a multiprogram laboratory operated for DOE by Battelle Memorial Institute under contract DE-AC05-76RL01830.

Edited by: M. Krämer

\section{References}

Adler, R. F., Huffman, G. J., Chang, A., Ferraro, R., Xie, P.-P., Janowiak, J., Rudolf, B., Schneider, U., Curtis, S., Bolvin, D., Gruber, A., Susskind, J., Arkin, P., and Nelkin, E.: The Version-2 Global Precipitation Climatology Project (GPCP) Monthly Precipitation Analysis (1979Present), J. Hydrometeor., 4, 1147-1167, doi:10.1175/15257541(2003)004<1147:TVGPCP>2.0.CO;2, 2003.

Andrews, T., Forster, P. M., Boucher, O., Bellouin, N., and Jones, A.: Precipitation, radiative forcing and global temperature change, Geophys. Res. Lett., 37, L14701, doi:10.1029/2010GL043991, 2010.

Barahona, D. and Nenes, A.: Parameterization of cirrus cloud formation in large-scale models: Homogeneous nucleation, J. Geophys. Res.-Atmos., 113, D11211, doi:10.1029/2007JD009355, 2008.

Barahona, D. and Nenes, A.: Parameterizing the competition between homogeneous and heterogeneous freezing in ice cloud formation - polydisperse ice nuclei, Atmos. Chem. Phys., 9, 59335948, doi:10.5194/acp-9-5933-2009, 2009.

Barahona, D. and Nenes, A.: Dynamical states of low temperature cirrus, Atmos. Chem. Phys., 11, 3757-3771, doi:10.5194/acp11-3757-2011, 2011.

Barahona, D., Molod, A., Bacmeister, J., Nenes, A., Gettelman, A., Morrison, H., Phillips, V., and Eichmann, A.: Development of two-moment cloud microphysics for liquid and ice within the NASA Goddard Earth Observing System Model (GEOS-5),
Geosci. Model Dev., 7, 1733-1766, doi:10.5194/gmd-7-17332014, 2014.

Bretherton, C. S. and Park, S.: A New Moist Turbulence Parameterization in the Community Atmosphere Model, J. Climate, 22, 3422-3448, doi:10.1175/2008JCLI2556.1, 2009.

Chen, T., Rossow, W. B., and Zhang, Y.: Radiative Effects of CloudType Variations, J. Climate, 13, 264-286, doi:10.1175/15200442(2000)013<0264:REOCTV> 2.0.CO;2, 2000.

Corti, T., Luo, B. P., Peter, T., Vomel, H., and Fu, Q.: Mean radiative energy balance and vertical mass fluxes in the equatorial upper troposphere and lower stratosphere, Geophys. Res. Lett., 32, L06802, doi:10.1029/2004GL021889, 2005.

Cziczo, D. J., Murphy, D. M., Hudson, P. K., and Thomson, D. S.: Single particle measurements of the chemical composition of cirrus ice residue during CRYSTAL-FACE, J. Geophys. Res.Atmos., 109, D04201, doi:10.1029/2003jd004032, 2004.

Cziczo, D. J., Froyd, K. D., Hoose, C., Jensen, E. J., Diao, M., Zondlo, M. A., Smith, J. B., Twohy, C. H., and Murphy, D. M.: Clarifying the Dominant Sources and Mechanisms of Cirrus Cloud Formation, Science, 340, 1320-1324, doi:10.1126/science.1234145, 2013.

DeMott, P. J., Cziczo, D. J., Prenni, A. J., Murphy, D. M., Kreidenweis, S. M., Thomson, D. S., Borys, R., and Rogers, D. C.: Measurements of the concentration and composition of nuclei for cirrus formation, P. Natl. Acad. Sci. USA, 100, 14655-14660, doi:10.1073/pnas.2532677100, 2003.

DeMott, P. J., Möhler, O., Stetzer, O., Vali, G., Levin, Z., Petters, M. D., Murakami, M., Leisner, T., Bundke, U., Klein, H., Kanji, Z. A., Cotton, R., Jones, H., Benz, S., Brinkmann, M., Rzesanke, D., Saathoff, H., Nicolet, M., Saito, A., Nillius, B., Bingemer, H., Abbatt, J., Ardon, K., Ganor, E., Georgakopoulos, D. G., and Saunders, C.: Resurgence in Ice Nuclei Measurement Research, B. Am. Meteorol. Soc., 92, 1623-1635, doi:10.1175/2011BAMS3119.1, 2011.

Diao, M., Zondlo, M. A., Heymsfield, A. J., Beaton, S. P., and Rogers, D. C.: Evolution of ice crystal regions on the microscale based on in situ observations, Geophys. Res. Lett., 40, 3473 3478, doi:10.1002/grl.50665, 2013.

Diao, M., Zondlo, M. A., Heymsfield, A. J., Avallone, L. M., Paige, M. E., Beaton, S. P., Campos, T., and Rogers, D. C.: Cloudscale ice-supersaturated regions spatially correlate with high water vapor heterogeneities, Atmos. Chem. Phys., 14, 2639-2656, doi:10.5194/acp-14-2639-2014, 2014.

Field, P. R., Heymsfield, A. J., and Bansemer, A.: Shattering and Particle Interarrival Times Measured by Optical Array Probes in Ice Clouds, J. Atmos. Ocean. Tech., 23, 1357-1371, doi:10.1175/JTECH1922.1, 2006.

Fusina, F., Spichtinger, P., and Lohmann, U.: Impact of ice supersaturated regions and thin cirrus on radiation in the midlatitudes, J. Geophys. Res., 112, D24S14, doi:10.1029/2007jd008449, 2007.

Gettelman, A., Morrison, H., and Ghan, S. J.: A new twomoment bulk stratiform cloud microphysics scheme in the community atmosphere model, version 3 (CAM3). Part II: Single-colunm and global results, J. Climate, 21, 3660-3679, doi:10.1175/2008jcli2116.1, 2008.

Gettelman, A., Liu, X., Ghan, S. J., Morrison, H., Park, S., Conley, A. J., Klein, S. A., Boyle, J., Mitchell, D. L., and Li, J. L. F.: Global simulations of ice nucleation and ice supersaturation with an improved cloud scheme in the Community 
Atmosphere Model, J. Geophys. Res.-Atmos., 115, D18216, doi:10.1029/2009jd013797, 2010.

Gettelman, A., Liu, X., Barahona, D., Lohmann, U., and Chen, C.: Climate impacts of ice nucleation, J. Geophys. Res.-Atmos., 117, D20201, doi:10.1029/2012jd017950, 2012.

Ghan, S. J.: Technical Note: Estimating aerosol effects on cloud radiative forcing, Atmos. Chem. Phys., 13, 9971-9974, doi:10.5194/acp-13-9971-2013, 2013.

Ghan, S. J., Liu, X., Easter, R. C., Zaveri, R., Rasch, P. J., Yoon, J. H., and Eaton, B.: Toward a Minimal Representation of Aerosols in Climate Models: Comparative Decomposition of Aerosol Direct, Semidirect, and Indirect Radiative Forcing, J. Climate, 25, 6461-6476, doi:10.1175/jcli-d-11-00650.1, 2012.

Greenwald, T. J., Stephens, G. L., Haar, T. H. V., and Jackson, D. L.: A physical retrieval of cloud liquid water over the global Oceans using Special Sensor Microwave/Imager (SSM/I) observations, J. Geophys. Res., 98, 18471-18488, 1993.

Haag, W.: The impact of aerosols and gravity waves on cirrus clouds at midlatitudes, J. Geophys. Res., 109, D12202, doi:10.1029/2004JD004579, 2004.

Han, Q., Rossow, W. B., and Lacis, A. A.: Near-Global Survey of Effective Droplet Radii in Liquid Water Clouds Using ISCCP Data, J. Climate, 7, 465-497, doi:10.1175/15200442(1994)007<0465:NGSOED>2.0.CO;2, 1994.

Hendricks, J., Kärcher, B., and Lohmann, U.: Effects of ice nuclei on cirrus clouds in a global climate model, J. Geophys. Res.Atmos., 116, D18206, doi:10.1029/2010JD015302, 2011.

Heymsfield, A. J., Miloshevich, L. M., Schmitt, C., Bansemer, A., Twohy, C., Poellot, M. R., Fridlind, A., and Gerber, H.: Homogeneous Ice Nucleation in Subtropical and Tropical Convection and Its Influence on Cirrus Anvil Microphysics, J. Atmos. Sci., 62, 41-64, doi:10.1175/JAS-3360.1, 2005.

Hoose, C. and Möhler, O.: Heterogeneous ice nucleation on atmospheric aerosols: a review of results from laboratory experiments, Atmos. Chem. Phys., 12, 9817-9854, doi:10.5194/acp-12-98172012, 2012.

Hoyle, C. R., Luo, B. P., and Peter, T.: The origin of high ice crystal number densities in cirrus clouds, J. Atmos. Sci., 62, 2568-2579, doi:10.1175/JAS3487.1, 2005.

Iacono, M. J., Delamere, J. S., Mlawer, E. J., Shephard, M. W., Clough, S. A., and Collins, W. D.: Radiative forcing by long-lived greenhouse gases: Calculations with the AER radiative transfer models, J. Geophys. Res.-Atmos., 113, D13103, doi:10.1029/2008jd009944, 2008.

IPCC: Climate Change 2007: The Physical Basis. Contribution of Working Group I to the Fourth Assessment Report of the Intergovernmental Panel on Climate Change, Cambridge Univ. Press, New York, 2007.

IPCC: Climate Change 2013: The Physical Science Basis. Contribution of Working Group I to the Fifth Assessment Report of the Intergovernmental Panel on Climate Change. Cambridge University Press, Cambridge Univ. Press, New York, 1535 pp., doi:10.1017/CBO9781107415324, 2013.

Jensen, E. J., Pfister, L., Bui, T.-P., Lawson, P., and Baumgardner, D.: Ice nucleation and cloud microphysical properties in tropical tropopause layer cirrus, Atmos. Chem. Phys., 10, 1369-1384, doi:10.5194/acp-10-1369-2010, 2010.

Jensen, E. J., Pfister, L., and Bui, T. P.: Physical processes controlling ice concentrations in cold cirrus near the trop- ical tropopause, J. Geophys. Res.-Atmos., 117, D11205, doi:10.1029/2011JD017319, 2012.

Jensen, E. J., Diskin, G., Lawson, R. P., Lance, S., Bui, T. P., Hlavka, D., McGill, M., Pfister, L., Toon, O. B., and Gao, R.: Ice nucleation and dehydration in the Tropical Tropopause Layer, P. Natl. Acad. Sci., 110, 2041-2046, doi:10.1073/pnas.1217104110, 2013.

Kärcher, B. and Burkhardt, U.: A cirrus cloud scheme for general circulation models, Q. J. Roy. Meteor. Soc., 134, 1439-1461, doi:10.1002/qj.301, 2008.

Kärcher, B. and Lohmann, U.: A parameterization of cirrus cloud formation: Homogeneous freezing of supercooled aerosols, J. Geophys. Res.-Atmos., 107, AAC 4-1-AAC 4-10, doi:10.1029/2001JD000470, 2002a.

Kärcher, B. and Lohmann, U.: A Parameterization of cirrus cloud formation: Homogeneous freezing including effects of aerosol size, J. Geophys. Res.-Atmos., 107, 4698, doi:10.1029/2001JD001429, 2002b.

Kärcher, B. and Lohmann, U.: A parameterization of cirrus cloud formation: Heterogeneous freezing, J. Geophys. Res.-Atmos., 108, 4402, doi:10.1029/2002JD003220, 2003.

Kärcher, B., Hendricks, J., and Lohmann, U.: Physically based parameterization of cirrus cloud formation for use in global atmospheric models, J. Geophys. Res.-Atmos., 111, D01205, doi:10.1029/2005JD006219, 2006.

Kärcher, B., Möhler, O., DeMott, P. J., Pechtl, S., and Yu, F.: Insights into the role of soot aerosols in cirrus cloud formation, Atmos. Chem. Phys., 7, 4203-4227, doi:10.5194/acp-7-4203-2007, 2007.

Kay, J. E., Baker, M., and Hegg, D.: Microphysical and dynamical controls on cirrus cloud optical depth distributions, J. Geophys. Res.-Atmos., 111, D24205, doi:10.1029/2005jd006916, 2006.

Kiehl, J. T. and Trenberth, K. E.: Earth's Annual Global Mean Energy Budget, B. Am. Meteorol. Soc., 78, 197-208, doi:10.1175/1520-0477(1997)078<0197:EAGMEB>2.0.CO;2, 1997.

Koop, T.: Homogeneous ice nucleation in water and aqueous solutions, Z. Phys. Chem., 218, 1231-1258, doi:10.1524/zpch.218.11.1231.50812, 2004.

Koop, T., Luo, B. P., Tsias, A., and Peter, T.: Water activity as the determinant for homogeneous ice nucleation in aqueous solutions, Nature, 406, 611-614, doi:10.1038/35020537, 2000.

Korolev, A. and Isaac, G. A.: Relative humidity in liquid, mixed-phase, and ice clouds, J. Atmos. Sci., 63, 2865-2880, doi:10.1175/JAS3784.1, 2006.

Krämer, M., Schiller, C., Afchine, A., Bauer, R., Gensch, I., Mangold, A., Schlicht, S., Spelten, N., Sitnikov, N., Borrmann, S., de Reus, M., and Spichtinger, P.: Ice supersaturations and cirrus cloud crystal numbers, Atmos. Chem. Phys., 9, 3505-3522, doi:10.5194/acp-9-3505-2009, 2009.

Kuebbeler, M., Lohmann, U., Hendricks, J., and Kärcher, B.: Dust ice nuclei effects on cirrus clouds, Atmos. Chem. Phys., 14, 3027-3046, doi:10.5194/acp-14-3027-2014, 2014.

Lamarque, J.-F., Bond, T. C., Eyring, V., Granier, C., Heil, A., Klimont, Z., Lee, D., Liousse, C., Mieville, A., Owen, B., Schultz, M. G., Shindell, D., Smith, S. J., Stehfest, E., Van Aardenne, J., Cooper, O. R., Kainuma, M., Mahowald, N., McConnell, J. R., Naik, V., Riahi, K., and van Vuuren, D. P.: Historical (1850-2000) gridded anthropogenic and biomass burning 
emissions of reactive gases and aerosols: methodology and application, Atmos. Chem. Phys., 10, 7017-7039, doi:10.5194/acp10-7017-2010, 2010.

Lawson, R. P.: Effects of ice particles shattering on the 2D-S probe, Atmos. Meas. Tech., 4, 1361-1381, doi:10.5194/amt-4-13612011, 2011.

Li, J. L. F., Waliser, D. E., Chen, W. T., Guan, B., Kubar, T., Stephens, G., Ma, H. Y., Deng, M., Donner, L., Seman, C., and Horowitz, L.: An observationally based evaluation of cloud ice water in CMIP3 and CMIP5 GCMs and contemporary reanalyses using contemporary satellite data, J. Geophys. Res.-Atmos., 117, D16105, doi:10.1029/2012JD017640, 2012.

Liou, K. N.: Influence of Cirrus Clouds on Weather and Climate Processes - a Global Perspective, Mon. Weather Rev., 114, 1167-1199, doi:10.1175/1520-0493(1986)114< 1167:IOCCOW> 2.0.CO;2, 1986.

Liu, X. H. and Penner, J. E.: Ice nucleation parameterization for global models, Meteorol. Z., 14, 499-514, doi:10.1127/09412948/2005/0059, 2005.

Liu, X., Penner, J. E., Ghan, S. J., and Wang, M.: Inclusion of Ice Microphysics in the NCAR Community Atmosphere Model Version 3 (CAM3), J. Climate, 20, 4526-4547, doi:10.1175/Jcli4264.1, 2007.

Liu, X., Penner, J. E., and Wang, M.: Influence of anthropogenic sulfate and black carbon on upper tropospheric clouds in the NCAR CAM3 model coupled to the IMPACT global aerosol model, J. Geophys. Res.-Atmos, 114, D03204, doi:10.1029/2008JD010492, 2009.

Liu, X., Shi, X., Zhang, K., Jensen, E. J., Gettelman, A., Barahona, D., Nenes, A., and Lawson, P.: Sensitivity studies of dust ice nuclei effect on cirrus clouds with the Community Atmosphere Model CAM5, Atmos. Chem. Phys., 12, 12061-12079, doi:10.5194/acp-12-12061-2012, 2012a.

Liu, X., Easter, R. C., Ghan, S. J., Zaveri, R., Rasch, P., Shi, X., Lamarque, J. F., Gettelman, A., Morrison, H., Vitt, F., Conley, A., Park, S., Neale, R., Hannay, C., Ekman, A. M. L., Hess, P., Mahowald, N., Collins, W., Iacono, M. J., Bretherton, C. S., Flanner, M. G., and Mitchell, D.: Toward a minimal representation of aerosols in climate models: description and evaluation in the Community Atmosphere Model CAM5.3, Geosci. Model Dev., 5, 709-739, doi:10.5194/gmd-5-709-2012, 2012b.

Loeb, N. G., Wielicki, B. A., Doelling, D. R., Smith, G. L., Keyes, D. F., Kato, S., Manalo-Smith, N., and Wong, T.: Toward Optimal Closure of the Earth's Top-of-Atmosphere Radiation Budget, J. Climate, 22, 748-766, doi:10.1175/2008JCLI2637.1, 2009.

Lohmann, U. and Feichter, J.: Global indirect aerosol effects: a review, Atmos. Chem. Phys., 5, 715-737, doi:10.5194/acp-5-7152005, 2005.

Lohmann, U., Spichtinger, P., Jess, S., Peter, T., and Smit, H.: Cirrus cloud formation and ice supersaturated regions in a global climate model, Environ. Res. Lett., 3, 045022, doi:10.1088/17489326/3/4/045022, 2008.

Meyers, M. P., Demott, P. J., and Cotton, W. R.: New Primary Ice-Nucleation Parameterizations in an Explicit Cloud Model, J. Appl. Meteorol., 31, 708-721, doi:10.1175/15200450(1992)031<0708:NPINPI>2.0.CO;2, 1992.

Morrison, H. and Gettelman, A.: A new two-moment bulk stratiform cloud microphysics scheme in the community atmosphere model, version 3 (CAM3). Part I: Description and numerical tests, J. Climate, 21, 3642-3659, doi:10.1175/2008jcli2105.1, 2008.

Murphy, D. M.: Rare temperature histories and cirrus ice number density in a parcel and a one-dimensional model, Atmos. Chem. Phys., 14, 13013-13022, doi:10.5194/acp-14-13013-2014, 2014.

Murray, B. J.: Inhibition of ice crystallisation in highly viscous aqueous organic acid droplets, Atmos. Chem. Phys., 8, 54235433, doi:10.5194/acp-8-5423-2008, 2008.

Murray, B. J., Wilson,T.W., Dobbie, S., Cui, Z., Al-Jumur, S. M. R. K., Möhler, O., Schnaiter, M., Wagner, R., Benz,S., Niemand, M., Saathoff, H., Ebert, V., Wagner, S., and Kärcher, B.: Heterogeneous nucleation of ice particles on glassy aerosols under cirrus conditions, Nat. Geosci., 3, 233-236, doi:10.1038/ngeo817, 2010.

Neale, R. B., Gettelman, A., Park, S., Conley, A. J., Kinnison, D., Marsh, D., Smith, A. K., Vitt, F., Morrison, H., Cameron-Smith, P., Collins, W. D., Iacono, M. J., Easter, R. C., Liu, X., and Taylor, M. A.: Description of the NCAR Community Atmosphere Model (CAM 5.0), NCAR Tech. Note NCAR/TN-485+STR, Natl. Cent. for Atmos. Res, Boulder, Co, 289 pp., 2012.

Phillips, V. T. J., DeMott, P. J., and Andronache, C.: An empirical parameterization of heterogeneous ice nucleation for multiple chemical species of aerosol, J. Atmos. Sci., 65, 2757-2783, doi:10.1175/2007jas2546.1, 2008.

Platnick, S., King, M. D., Ackerman, S. A., Menzel, W. P., Baum, B. A., Riedi, J. C., and Frey, R. A.: The MODIS cloud products: algorithms and examples from Terra, IEEE T. Geosci. Remote, 41, 459-473, doi:10.1109/TGRS.2002.808301, 2003.

Pruppacher, H. R. and Klett, J. D.: Microphysics of Cloud and Precipitation, Springer, New York, 954 pp., 1997.

Rossow, W. B. and Schiffer, R. A.: Advances in Understanding Clouds from ISCCP, B. Am. Meteorol. Soc., 80, 2261-2287, doi:10.1175/1520-0477(1999)080< 2261:AIUCFI> 2.0.CO;2, 1999.

Salzmann, M., Ming, Y., Golaz, J.-C., Ginoux, P. A., Morrison, H., Gettelman, A., Krämer, M., and Donner, L. J.: Two-moment bulk stratiform cloud microphysics in the GFDL AM3 GCM: description, evaluation, and sensitivity tests, Atmos. Chem. Phys., 10, 8037-8064, doi:10.5194/acp-10-8037-2010, 2010.

Shi, X., Wang, B., Liu, X., and Wang, M.: Two-moment bulk stratiform cloud microphysics in the grid-point atmospheric model of IAP LASG (GAMIL), Adv. Atmos. Sci., 30, 868-883, doi:10.1007/s00376-012-2072-1, 2013.

Spichtinger, P. and Gierens, K. M.: Modelling of cirrus clouds - Part 2: Competition of different nucleation mechanisms, Atmos. Chem. Phys., 9, 2319-2334, doi:10.5194/acp-9-2319-2009, 2009.

Spichtinger, P. and Krämer, M.: Tropical tropopause ice clouds: a dynamic approach to the mystery of low crystal numbers, Atmos. Chem. Phys., 13, 9801-9818, doi:10.5194/acp-13-98012013, 2013.

Szyrmer, W. and Zawadzki, I.: Biogenic and anthropogenic sources of ice-forming nuclei: A review, B Am. Meteorol. Soc., 78, 209-228, doi:10.1175/15200477(1997)078<0209:BAASOI>2.0.CO;2, 1997.

Wang, M. and Penner, J. E.: Cirrus clouds in a global climate model with a statistical cirrus cloud scheme, Atmos. Chem. Phys., 10, 5449-5474, doi:10.5194/acp-10-5449-2010, 2010. 
Wang, P.-H., Minnis, P., McCormick, M. P., Kent, G. S., Yue, G. K., Young, D. F., and Skeens, K. M.: A 6-year climatology of cloud occurence frequency from Stratospheric Aerosol and Gas experiment II observations (1985-1990), J. Geophys. Res., 101, 407-429, doi:10.1029/96JD01780, 1996.

Wang, M., Liu, X., Zhang, K., and Comstock, J. M.: Aerosol effects on cirrus through ice nucleation in the Community Atmosphere Model CAM5 with a statistical cirrus scheme, J. Adv. Model. Earth Syst., 06, doi:10.1002/2014MS000339, 2014.

Weng, F. Z. and Grody, N. C.: Retrieval of cloud liquid water using the Special Sensor Microwave Imager (SSM/I), J. Geophys. Res., 99, 25535-25551, 1994.

Wielicki, B. A., Barkstrom, B. R., Harrison, E. F., Lee, R. B., Louis Smith, G., and Cooper, J. E.: Clouds and the Earth's Radiant Energy System (CERES): An Earth Observing System Experiment, B. Am. Meteorol. Soc., 77, 853-868, doi:10.1175/15200477(1996)077<0853:CATERE>2.0.CO;2, 1996.

Wylie, D. P. and Menzel, W. P.: Eight years of high cloud statistics using HIRS, J. Climate, 12, 170-184, doi:10.1175/1520-044212.1.170, 1999.
Wylie, D., Jackson, D. L., Menzel, W. P., and Bates, J. J.: Trends in Global Cloud Cover in Two Decades of HIRS Observations, J. Climate, 18, 3021-3031, doi:10.1175/JCLI3461.1, 2005.

Zhang, K., O’Donnell, D., Kazil, J., Stier, P., Kinne, S., Lohmann, U., Ferrachat, S., Croft, B., Quaas, J., Wan, H., Rast, S., and Feichter, J.: The global aerosol-climate model ECHAM-HAM, version 2: sensitivity to improvements in process representations, Atmos. Chem. Phys., 12, 8911-8949, doi:10.5194/acp-12-89112012, 2012.

Zhang, K., Liu, X., Wang, M., Comstock, J. M., Mitchell, D. L., Mishra, S., and Mace, G. G.: Evaluating and constraining ice cloud parameterizations in CAM5 using aircraft measurements from the SPARTICUS campaign, Atmos. Chem. Phys., 13, 4963-4982, doi:10.5194/acp-13-4963-2013, 2013a.

Zhang, K., Liu, X., Comstock, J., Wang, M., Wan, H., and Bui, T.: Vertical Draft Velocity in Cirrus Clouds and Long-Wave Aerosol Indirect Effect, The Atmosphere Model Working Group Meeting, 11-13 February 2013, Boulder, Colorado, 2013b. 